\title{
Effects of post-translational modifications catalysed by pollen transglutaminase on the functional properties of microtubules and actin filaments
}

\author{
Stefano DEL DUCA*, Donatella SERAFINI-FRACASSINI*, Philip BONNER $\dagger$, Mauro CRESTI $\ddagger$ and Giampiero CAl ${ }^{1}$ \\ ${ }^{*}$ Dipartimento di Biologia Evoluzionistica Sperimentale, Sede Botanica, University of Bologna, via Irnerio 42, 40126 Bologna, Italy, $†$ School of Biomedical and Natural Sciences, \\ Nottingham Trent University, Nottingham NG11 8NS, U.K., and łDipartimento Scienze Ambientali, University of Sienna, via Mattioli 4, 53100 Siena, Italy
}

\begin{abstract}
TGases (transglutaminases) are a class of calcium-dependent enzymes that catalyse the interactions between acyl acceptor glutamyl residues and amine donors, potentially making crosslinks between proteins. To assess the activity of apple (Malus domestica) pollen TGase on the functional properties of actin and tubulin, TGase was prepared from apple pollen by hydrophobic interaction chromatography and assayed on actin and tubulin purified from the same cell type. The enzyme catalysed the incorporation of putrescine in the cytoskeleton monomers. When tested on actin filaments, pollen TGase induced the formation of high-molecular-mass aggregates of actin. Use of fluoresceincadaverine showed that the labelled polyamine was incorporated into actin by pollen TGase, similar to with guinea pig liver TGase. The pollen TGase also reduced the enzyme activity and
\end{abstract}

the binding of myosin to TGase-treated actin filaments. Polymerization of tubulin in the presence of pollen TGase also yielded the formation of high molecular mass aggregates. Furthermore, the pollen TGase also affected the binding of kinesin to microtubules and reduced the motility of microtubules along kinesincoated slides. These results indicate that the pollen TGase can control different properties of the pollen tube cytoskeleton (including the ability of actin and tubulin to assemble and their interaction with motor proteins) and consequently regulate the development of pollen tubes.

Key words: actin filament, kinesin, microtubule, plant transglutaminase, myosin, pollen tube.

\section{INTRODUCTION}

The pollen is the male gametophyte of seed plants and its tube transports the male gametes toward the egg cell. The growth of pollen tubes is a complex process that needs the simultaneous activity of many different molecules working in the apical domain [1]. The movement of cytoplasmic content of pollen tubes is dependent on the pollen tube cytoskeleton [2], which consists essentially of microtubules, actin filaments and related proteins organized to facilitate and promote the unidirectional cell expansion and the transport of sperm cells. Actin filaments are generally widespread in the pollen tube cytoplasm but are absent in the very tip; a consistent "actin fringe" is present immediately behind the tip and is thought to delimit the growth area [3]. On the contrary, microtubules are preferentially organized as bundles in the cortical cytoplasm and are absent in the last $10-20 \mu \mathrm{m}$ of the tube apex [4]. Actin filaments are mainly involved in organelle movement and in tube growth [5]; on the other hand, microtubules may play a role in the transport of sperm cells [6], probably participate in the regulation of organelle movement [4] and might also guide pollen tube growth in vivo or have a role in directing the elongation activity [7].

Tubulin is post-translationally modified to realize its multitude of functions during pollen tube growth [8]. On the other hand, post-translational modifications of actin are poorly known in eukaryotic cells [9]. An important form of post-translational modification is the conjugation of polyamines, which is mediated by calcium-dependent TGases (transglutaminases; E.C. 2.3.2.13). TGases catalyse the interaction between an acyl acceptor glutamyl residue and amine donors, like lysyl residues, thus forming crosslinks within the same or different proteins. Polyamines also act as physiological substrates of TGases: their terminal aminogroup binds one or two glutamyl residues, giving rise to either mono- $(\gamma$-glutamyl)-polyamines or bis-( $\gamma$-glutamyl)-polyamines $[10,11]$. Consequently, the 'bridge' between two proteins has different lengths: very short for the Lys-Gln binding, and gradually longer for polyamines with different backbone length. Moreover, polyamines exhibit positive charge and thus 'cationise' the partner protein. TGases form bridges between specific proteins, including cytoskeleton proteins or extracellular matrix proteins, and are probably involved in the regulation of cell growth and differentiation of animal and plant cells [12]. TGases are also defined as "biological glues" for their capacity to join proteins [13]. Previous results from animal cells suggested the involvement of TGase in the modification of cytoskeleton proteins. After early indications that actin is a substrate of TGase [14], actin in Physarum was recognized as such [15]. Recently, the cytoskeleton substrates of TGase 2, one of the nine TGases identified in animals, were summarized by Robinson et al. [16]. Polyamines are also involved in the rearrangement of actin and tubulin cytoskeleton as demonstrated by Pohjanpelto et al. [17] in $\mathrm{CHO}$ (Chinese hamster ovary) dividing cells.

The crude extract of apple (Malus domestica) pollen contained unpurified TGase activity and catalysed the incorporation of polyamines into proteins with molecular masses of $43 \mathrm{kDa}$ and $52-58 \mathrm{kDa}$ [18]. These bands matched immunolabelled spots identified by mouse monoclonal antibodies to actin and $\alpha$-tubulin. The supply of exogenous actin and tubulin in cell-free extracts

Abbreviations used: ANP, N-(4-azido-2-nitrophenyl)-putrescine; DIC, differential interference contrast; DTT, dithiothreitol; gplTGase; guinea pig liver transglutaminase; HIC, hydrophobic interaction chromatography; TGase, transglutaminase.

1 To whom correspondence should be addressed (email cai@unisi.it). 
of pollen enhanced the TGase activity. Moreover, actin of germinating pollen gave rise to cross-linked products of high molecular mass [18].

The present study was undertaken to analyse the involvement of purified pollen TGase in the post-translational modification of pollen actin and tubulin via Gln-Lys or polyamine bridges. Pollen from Malus domestica was chosen as the starting material because apple pollen was already shown to catalyse the incorporation of polyamines (therefore it presumably contains a TGase activity) [18]. This work also assayed the polymerization/ depolymerization properties of actin and tubulin after modification by TGase. This possibility was studied by supplying two different amines, the FITC-cadaverine (for labelling the substrates), with only one amino group available for conjugation, and putrescine, with both the primary amino groups available for linkages and possible involvement in cross-bridge formation. We also assessed the TGase-induced modifications of actin/tubulin in connection with their related motor proteins, myosin and kinesin. Since the proper dynamic of actin filaments and microtubules, coupled to the activity of motor proteins, is responsible for organelle movement in pollen tubes [4], TGase may consequently be recognized to take part in the control of many active processes occurring during pollen tube growth.

\section{MATERIALS AND METHODS}

\section{Plant material}

Mature pollen of Malus domestica Borkh. cv. Red Chief was collected from experimental plots (Dipartimento di Colture Arboree, Bologna, Italy; Azienda Agricola Rondinini, Faenza, Italy). Handling and storage were performed as described by Bagni et al. [19].

\section{Antibodies and chemicals}

Rabbit antibody to plant actin was a generous gift of Dr. Richard Cyr (Department of Biology, Pennsylvania State University, PA, U.S.A.). Donkey polyclonal antibody to tubulin was purchased from Cytoskeleton (code number ATN02). Unless otherwise indicated, chemicals used in this work were purchased from Sigma-Aldrich. gplTGase (guinea pig liver TGase) was obtained from Sigma-Aldrich. The ID10 anti-TGase monoclonal antibody was raised against purified gplTGase; clones were screened out against gplTGase, ion exchange-purified extracts of 14-days old Pisum sativum leaves and against germinated Vicia faba cotyledons (used 14 days after imbibitions). ELISA-positive fractions were pooled, concentrated in a dialysis tube against PEG 8000 and stored at $-20^{\circ} \mathrm{C}$. The specificity of ID10 for pollen TGase was tested against partially purified enzyme fractions and was compared with that of the well-known TGase antibody AbIII (Neomarker, Fremont, CA, U.S.A.) already assayed against plant [20] and pollen [21] TGases; the two antibodies showed the same immunorecognition profile.

\section{Preparation of a pollen TGase-enriched fraction}

Pollen was rehydrated at $30^{\circ} \mathrm{C}$ with $100 \%$ relative humidity for $30 \mathrm{~min}$. All purification steps were conducted at $4^{\circ} \mathrm{C}$. One gram of hydrated pollen was extracted using a Potter-Elvehjem tissue homogenizer with $100 \mathrm{ml}$ of $25 \mathrm{mM}$ Tris buffer, pH 8.0, 2 mM DTT (dithiothreitol), $0.1 \mathrm{mM}$ PMSF and $1 \mathrm{mM}$ EDTA. The extract was centrifuged at $20400 \mathrm{~g}$ for $10 \mathrm{~min}$ and the supernatant was dialysed overnight against 5 litres of dialysis buffer $(5 \mathrm{mM}$ Tris buffer, $\mathrm{pH} 8.0$, and $1 \mathrm{mM} 2$-mercaptoethanol) with three changes of buffer. The dialysed sample was supplemented with $5 \mathrm{mM} \mathrm{CaCl}_{2}$ and centrifuged at $20400 \mathrm{~g}$ for $15 \mathrm{~min}$ to eliminate the calcium-induced protein precipitation. The supernatant was loaded on a Phenyl Sepharose HIC (hydrophobic interaction chromatography) column $(1.6 \times 25 \mathrm{~cm}$, Sigma-Aldrich), and equilibrated with $20 \mathrm{mM}$ Tris buffer, $\mathrm{pH} 8.0$, containing $5 \mathrm{mM}$ $\mathrm{CaCl}_{2}$ and $1 \mathrm{mM}$ 2-mercaptoethanol. Elution was performed at $2.5 \mathrm{ml} / \mathrm{min}$ with an isocratic flow of the same buffer containing EGTA instead of $\mathrm{CaCl}_{2}$, followed by two column washings with distilled water and ethylene glycol (50\% in water) respectively. Samples were dialysed overnight against 1000 volumes of $5 \mathrm{mM}$ Tris buffer, $\mathrm{pH} 8.0$, and $1 \mathrm{mM}$ 2-mercaptoethanol with three changes of buffer, then freeze-dried and stored at $-80^{\circ} \mathrm{C}$. Samples were diluted in $50 \mathrm{mM}$ Tris buffer, $\mathrm{pH} 8.0$, containing $1.5 \mathrm{mM}$ DTT and incubated for $5 \mathrm{~min}$ at room temperature $\left(?{ }^{\circ} \mathrm{C}\right)$ before assaying the TGase activity.

\section{Incorporation assay of biotin-labeled cadaverine by TGase}

Dialysed fractions from the HIC and the pollen extract were tested by the biotin-cadaverine incorporation assay according to Lilley et al. [22] with EGTA replacing $10 \mathrm{mM}$ EDTA in negative controls.

\section{Purification of actin from apple pollen}

Purification of actin from apple pollen was performed according to [23]. Hydrated apple pollen $(1 \mathrm{~g})$ was germinated for $3 \mathrm{~h}$ in the growth medium $\left(0.2 \mathrm{M}\right.$ sucrose, $0.33 \mathrm{mM} \mathrm{H}_{2} \mathrm{BO}_{3}$ and $1.3 \mathrm{mM}$ $\mathrm{Ca}_{2} \mathrm{NO}_{3}$ ) at the concentration of $1 \mathrm{mg} / \mathrm{ml}$. After germination, pollen was collected by centrifugation at $1000 \mathrm{~g}$ for $10 \mathrm{~min}$. The pellet was washed with washing buffer ( $2 \mathrm{mM} 2$-mercaptoethanol, $0.005 \% \mathrm{NaN}_{3}, 0.2 \mathrm{mM} \mathrm{CaCl}_{2}$ and $2 \mathrm{mM}$ Tris, pH 8.0) and the final pellet was suspended in $5 \mathrm{ml}$ of the lysis buffer 1 (buffer A: $2 \mathrm{mM}$ 2-mercaptoethanol, $0.2 \mathrm{mM}$ ATP, $0.005 \% \mathrm{NaN}_{3}$, $0.2 \mathrm{mM} \mathrm{CaCl}_{2}, 2 \mathrm{mM}$ Tris pH 8.0,1 mM PMSF and plant protease inhibitor cocktail from Sigma; code P9599). All purification steps were conducted at $4{ }^{\circ} \mathrm{C}$ unless otherwise stated. Cells were lysed with a Potter-Elvehjem Tissue Homogenizer. The homogenate was centrifuged at $10000 \mathrm{~g}$ for $20 \mathrm{~min}$. The supernatant was then centrifuged at $100000 \mathrm{~g}$ for $30 \mathrm{~min}$. The pellet was discarded, while the supernatant was precipitated with $2.2 \mathrm{M}\left(\mathrm{NH}_{4}\right)_{2} \mathrm{SO}_{4}$ under agitation. After $10 \mathrm{~min}$, the sample was centrifuged at $10000 \mathrm{~g}$ for $10 \mathrm{~min}$. The resulting pellet was dissolved in $2 \mathrm{ml}$ of buffer $\mathrm{B}(0.1 \mathrm{mM} \mathrm{CaCl}, 2 \mathrm{mM} \beta$-mercaptoethanol, $10 \mathrm{mM}$ imidazole $\mathrm{pH} 7.5,0.5 \mathrm{mM}$ ATP, $0.05 \% \mathrm{NaN}_{3}$ and $1 \mathrm{mM}$ PMSF) and dialysed overnight against buffer B. The sample was fractionated using a Mono-Q HR 5/5 column (GE HealthCare), equilibrated in buffer B over 20 column volumes $(19.6 \mathrm{ml})$ with a linear gradient from 0 to $1 \mathrm{M} \mathrm{KCl}$; elution was performed at $1 \mathrm{ml} / \mathrm{min}$ at room temperature. Fractions were analysed by spot-test with a plant actin antibody. Cross-reacting fractions were pooled and supplemented with $2 \mathrm{mM} \mathrm{MgCl}$. After $10 \mathrm{~h}$ incubation at $4{ }^{\circ} \mathrm{C}$ to stimulate actin polymerization, the sample was centrifuged at $160000 \mathrm{~g}$ for $1 \mathrm{~h} 45 \mathrm{~min}$. The pellet was dissolved in $300 \mu \mathrm{l}$ of buffer $\mathrm{C}(2 \mathrm{mM} 2$-mercaptoethanol, $0.2 \mathrm{mM}$ ATP, $0.005 \% \mathrm{NaN}_{3}, 0.2 \mathrm{mM} \mathrm{CaCl}_{2}, 2 \mathrm{mM}$ Tris, pH 8.0, and $1 \mathrm{mM}$ PMSF) and dialysed overnight against buffer $\mathrm{C}$ using the $8 \mathrm{kDa}$ Cut-Off Mini Dialysis kit (GE HealthCare). The sample was fractionated onto a Superdex 200 HR 10/30 column (GE HealthCare) and equilibrated with buffer $\mathrm{C}$ at room temperature with a flow rate of $0.8 \mathrm{ml} / \mathrm{min}$. Chromatography steps were performed using a AKTA Purifier system (GE HealthCare). Fractions were assayed by spot-test with the actin antibody and positive fractions were pooled, frozen in liquid nitrogen and stored at $-80^{\circ} \mathrm{C}$. 


\section{Purification of tubulin from apple pollen}

Tubulin from apple pollen was purified according to the literature [24]. Apple pollen ( $1 \mathrm{~g}$ ) was germinated as described above and homogenized in $5 \mathrm{ml}$ of lysis buffer 2 containing $50 \mathrm{mM}$ Pipes, pH 6.8, $2 \mathrm{mM} \mathrm{MgCl}_{2}, 2 \mathrm{mM}$ EGTA, $1 \mathrm{mM}$ DTT, plant protease inhibitor cocktail from Sigma and 0.1 mM GTP. All steps were carried out at $4{ }^{\circ} \mathrm{C}$ unless otherwise mentioned. After high-speed centrifugation, the supernatant was fractionated onto a Resource $\mathrm{Q}$ anion exchange column $(1 \times 1 \mathrm{ml}$, GE HealthCare $)$ equilibrated

Q2 in buffer D (50 mM Pipes/KOH, pH 6.8, $2 \mathrm{mM} \mathrm{MgCl}_{2}, 2 \mathrm{mM}$ EGTA, $1 \mathrm{mM}$ DTT, $1 \mathrm{mM}$ PMSF and $0.1 \mathrm{mM}$ GTP). The sample was eluted over 20 column volumes $(20 \mathrm{ml})$ from 0 to $1 \mathrm{M} \mathrm{KCl}$ at room temperature with a flow rate of $1 \mathrm{ml} / \mathrm{min}$. Fractions were analysed by spot-test with tubulin antibodies and positive fractions pooled. The resulting $4 \mathrm{ml}$ sample was loaded onto a HiPrep 16/60 Sephacryl S-300 column (GE HealthCare) equilibrated with buffer $\mathrm{D}$ at room temperature; elution was achieved at $1 \mathrm{ml} / \mathrm{min}$. Fractions were again assayed by tubulin antibody. Cross-reacting fractions were pooled and applied to a Mono-Q HR 5/5 column equilibrated with buffer D. Protein separation was achieved over 20 column volumes $(19.6 \mathrm{ml})$ from 0 to $1 \mathrm{M} \mathrm{KCl}$ at room temperature, with a flow rate of $1 \mathrm{ml} / \mathrm{min}$. Fractions positive to the spot-test analysis were dialysed for several hours in Mini Dialysis kit $8 \mathrm{kDa}$ cut-off against buffer D. Chromatography steps were performed using a AKTA Purifier system (GE HealthCare). The sample was frozen under liquid nitrogen and stored at $-80^{\circ} \mathrm{C}$.

\section{TGase radiometric assay}

The in vitro reactivity of TGase with cytoskeleton proteins was performed as previously described by Serafini-Fracassini et al. [25], but modified as follows. The incubation mixture included $50 \mu \mathrm{l}$ of pollen actin or tubulin $(0.5 \mathrm{mg} / \mathrm{ml}), 15 \mu \mathrm{l}$ of $500 \mathrm{mM}$ Tris buffer, $\mathrm{pH} 8,2 \mu \mathrm{l}$ of TGase active fraction $(2 \mathrm{mg} / \mathrm{ml})$ and final concentrations of the following: $0.1 \mathrm{mM}$ putrescine, $10 \mathrm{mM}$ DTT and $2.5 \mathrm{mM} \mathrm{CaCl}_{2}$. As radioactive tracer, $444 \mathrm{kBq}[1,4(\mathrm{n})$ $\left.{ }^{3} \mathrm{H}\right]$-putrescine $\left(0.55 \mathrm{TBq}^{\mathrm{mmol}}{ }^{-1}\right.$; GE HealthCare) was added to the assay mixture for a total volume of $150 \mu \mathrm{l}$. After $120 \mathrm{~min}$ of incubation at $30^{\circ} \mathrm{C}$, the reaction was stopped and repeatedly pelleted with $5 \%(\mathrm{w} / \mathrm{v})$ trichloroacetic acid as described [26] and the radioactivity was counted. Another aliquot was used for the $\gamma$-glutamyl polyamine derivatives analysis (see below). Enzyme reactions were also carried out in the presence of the commercial TGase inhibitor 1,3-dimethyl-2-[(2-oxopropyl)thio] imidazolium chloride (Zedira).

\section{HPLC identification of $\gamma$-glutamyl polyamine derivatives}

The incorporation of labeled putrescine into TGase substrate proteins was evaluated in the trichloroacetic acid-insoluble fractions as mono- and bis- $\gamma$-glutamyl polyamine derivatives. The final pellet was washed at least three times with anhydrous diethyl ether and proteolysed according to Folk et al. [10]. The digestion products were separated by ion exchange chromatography using a Jasco HPLC system $(4.5 \times 90 \mathrm{~mm}$ column, packed with Ultropac 8 resin, $\mathrm{Na}^{+}$form; Jasco Europe, Milan, Italy) and the five-buffer system previously described by Folk et al. [10]. The identity of the polyamine derivatives was determined by comparison with the corresponding retention times of glutamyl polyamine standards. The identity of conjugated polyamines was determined after release of free polyamines by acid hydrolysis $(6 \mathrm{M} \mathrm{HCl})$ of the ion exchange chromatographic fractions corresponding with the predicted retention times [27].

\section{Assay of pollen TGase activity on actin filaments}

In order to determine the effects of pollen TGase on cytoskeleton proteins, actin (Cytoskeleton; AKL-99) was diluted to $0.4 \mathrm{mg} / \mathrm{ml}$ in A-buffer ( $5 \mathrm{mM}$ Tris/ $\mathrm{HCl}, \mathrm{pH} 8.0,0.2 \mathrm{mM}$ ATP and $0.2 \mathrm{mM}$ $\left.\mathrm{CaCl}_{2}\right)$ and incubated for $1 \mathrm{~h}$ on ice. Actin was added to the polymerization buffer $(0.5 \mathrm{M} \mathrm{KCl}, \mathrm{pH} 8.0,10 \mathrm{mM}$ ATP and $20 \mathrm{mM} \mathrm{MgCl}_{2}$ ) and incubated for $1 \mathrm{~h}$ at room temperature. Actin and pollen TGase were mixed at a ratio of 10:1 in the presence of $1 \mathrm{mM}$ FITC-labelled cadaverine and $7 \mathrm{mM} \mathrm{CaCl} \mathrm{Cl}_{2}$. All samples were incubated for $3 \mathrm{~h}$ at $37^{\circ} \mathrm{C}$. After incubation, $10 \mu \mathrm{l}$ aliquots were perfused within a perfusion chamber and further incubated for $5 \mathrm{~min}$. After brief staining with rhodaminephalloidin buffer $(10 \mu \mathrm{l}$ of $10 \times$ polymerization buffer, $25 \mu \mathrm{l}$ of $6.6 \mu \mathrm{M}$ rhodamine-phalloidin stock from Invitrogen and $65 \mu \mathrm{l}$ of water), samples were observed with a fluorescence microscope. Enzyme reaction of remaining samples was stopped by addition of $7 \mathrm{mM}$ EGTA. Samples were centrifuged at $15000 \mathrm{~g}$ for $1 \mathrm{~h}$ at $25^{\circ} \mathrm{C}$ and supernatants and pellets were processed for SDS/PAGE. Similar analysis was performed with rhodamine-labelled actin (Cytoskeleton, code number AR05); in this case, the rhodaminephalloidin buffer was not applied.

\section{Optical microscopy analysis of incorporation of FITC-cadaverine in actin filaments}

Samples were observed with a Zeiss Axiophot fluorescence microscope, equipped with a $63 \times$ objective. Images were captured with an MRc5 AxioCam video camera using AxioVision software. Samples were alternatively analysed with a Bio-Rad MicroRadiance Confocal microscope using a $63 \times$ objective.

\section{Binding and enzyme assay of myosin with TGase-treated actin filaments}

Actin filaments were prepared and treated with pollen TGase as described above. Myosin (Cytoskeleton, code MHO1) was diluted to $1 \mathrm{mg} / \mathrm{ml}$ in $4 \mathrm{mM}$ Tris/HCl, $\mathrm{pH} 7.6,2 \mathrm{mM} \mathrm{MgCl}_{2}$ and $100 \mathrm{mM}$ $\mathrm{KCl}$, and added to pre-treated actin filaments. After incubation for $30 \mathrm{~min}$ at $25^{\circ} \mathrm{C}$, samples were centrifuged at $15000 \mathrm{~g}$ for $1 \mathrm{~h}$ at $25^{\circ} \mathrm{C}$. Supernatants and pellets were processed for SDS/PAGE.

For the myosin enzyme assay, 10, 20 and $50 \mu \mathrm{l}$ of actin filaments were added to myosin in the ATPase assay buffer $(10 \mathrm{mM}$ $\mathrm{KCl}, 1 \mathrm{mM}$ EGTA, $2 \mathrm{mM} \mathrm{MgCl}_{2}, 5 \mathrm{mM}$ ATP and $20 \mathrm{mM}$ Pipes, $\mathrm{pH}$ 7.0). After incubation at $25^{\circ} \mathrm{C}$ for $5,10,20,25$ and $30 \mathrm{~min}$, the amount of free inorganic phosphate was measured using the PhosFree kit from Cytoskeleton. Controls were performed with gplTGase (same amount of pollen TGase).

\section{Polymerization/depolymerization assay of tubulin in the presence of pollen TGase}

Tubulin aliquots $(10 \mathrm{mg} / \mathrm{ml}$, from Cytoskeleton, rhodaminelabelled, code TL331M, or unlabelled, code TL238) were diluted with buffer E ( $80 \mathrm{mM}$ Hepes, pH 7.5, $1 \mathrm{mM}$ EGTA, $1 \mathrm{mM} \mathrm{MgCl}$, $2 \mathrm{mM} \mathrm{GTP}$ and $20 \%$ glycerol) at $5 \mathrm{mg} / \mathrm{ml}$. Tubulin samples were mixed with pollen TGase (10:1 ratio), $5 \mathrm{mM}$ FITC-cadaverine and $7 \mathrm{mM} \mathrm{CaCl}_{2}$. Samples were incubated at $37^{\circ} \mathrm{C}$ for $3 \mathrm{~h}$, and then observed at the optical microscope [DIC (differential interference contrast) view, see below]. Enzyme reaction was blocked by adding $7 \mathrm{mM}$ EGTA. Samples were centrifuged at $15000 \mathrm{~g}$ for $1 \mathrm{~h}$ at $25^{\circ} \mathrm{C}$, and supernatants were prepared for SDS/PAGE. Pellets were suspended in PEM buffer ( 80 mM Pipes, $\mathrm{pH}$ 6.8, $1 \mathrm{mM}$ EGTA and $1 \mathrm{mM} \mathrm{MgCl}_{2}$ ); part of this was prepared for SDS/PAGE and the remaining was incubated for $30 \mathrm{~min}$ at $4{ }^{\circ} \mathrm{C}$ (depolymerization phase). Afterward, samples were centrifuged at 

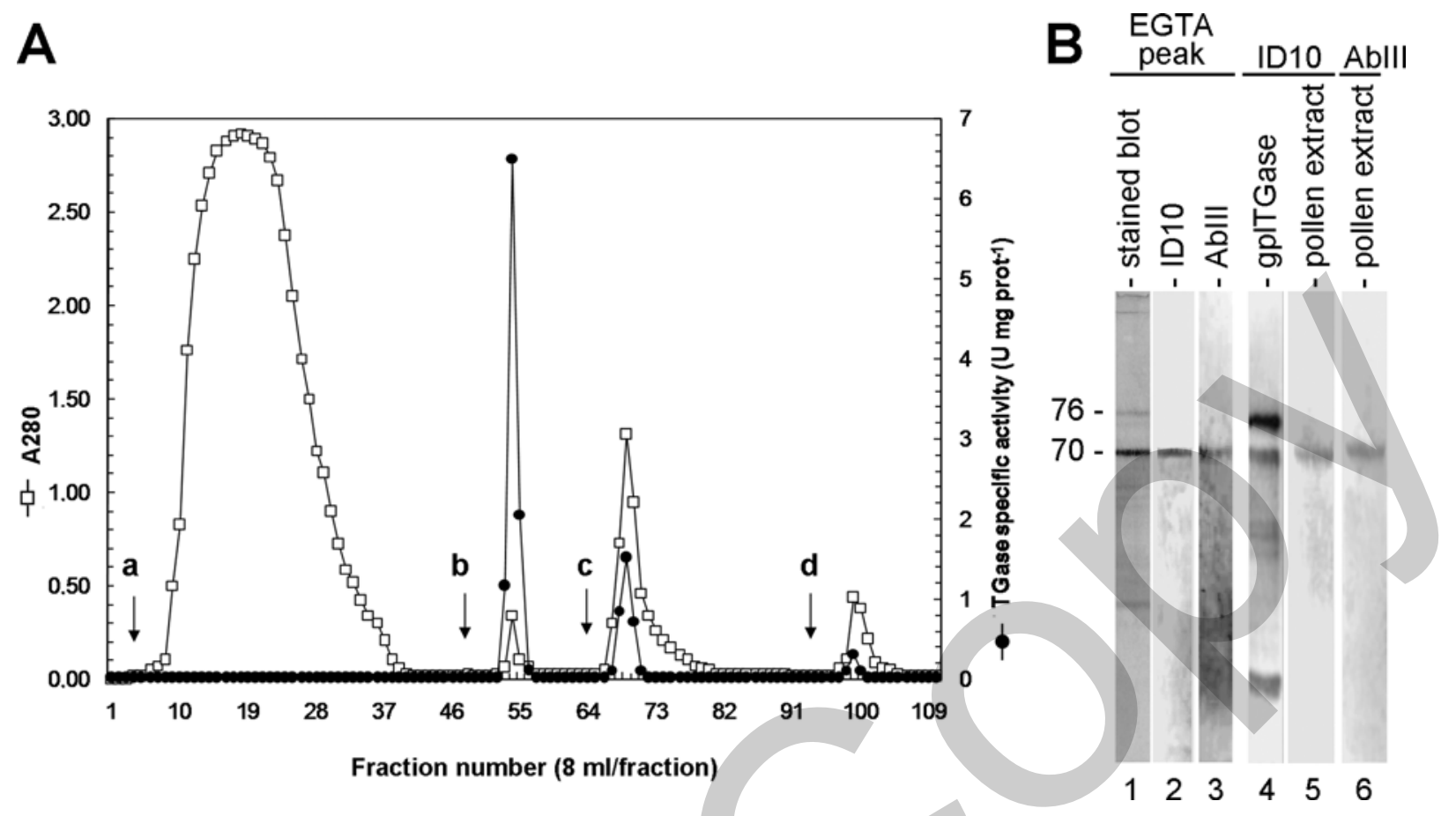

Figure 1 Isolation of TGase from apple pollen

(A) Hydrophobic interaction chromatography with Phenyl Sepharose of $50 \mathrm{ml}$ protein extract $(0.5 \mathrm{mg} / \mathrm{ml})$ from 30 min hydrated apple pollen. The black arrows indicate the starting isocratic flow of buffer containing (a) $5 \mathrm{mM} \mathrm{CaCl}_{2}$, (b) $10 \mathrm{mM}$ EGTA, (c) water and (d) $50 \%$ ethylene glycol in water. The left axis reports the protein absorbance $\left(A_{280}\right.$, $\square$ ), and the right axis reports the specific TGase activity (units per $\mathrm{mg}$ of protein, $\boldsymbol{\bullet}$ ) determined by the biotin-labelled cadaverine incorporation assay. (B) SDS/PAGE and immunoblot of pollen extract and EGTA eluted peak. Lane 1, Coomassie Blue stained EGTA-eluted peak blotted on PVDF membrane $(20 \mu \mathrm{g})$. Lane 2, immunoblot of the EGTA-eluted peak with the ID10 antibody. Lane 3, immunoblot of the EGTA-eluted peak with AbllI. Lane 4, ID10-probed blotted proteins from gplTGase. Lane 5, ID10 antibody probed on germinated pollen extract. Lane 6, Ablll probed on germinated pollen extract. The molecular mass of main bands is indicated on the left in $\mathrm{kDa}$ (and in all gels/blots of other Figures).

$15000 \mathrm{~g}$ for $1 \mathrm{~h}$ at $4{ }^{\circ} \mathrm{C}$ and supernatants and pellets were prepared for SDS/PAGE.

\section{DIC microscopy of TGase-treated microtubules}

Samples of treated and untreated microtubules were perfused into perfusion chambers and incubated for $5 \mathrm{~min}$. Slides were washed with PEM buffer and observed at the optical microscope in DIC view to assess the effects of TGase-mediated incorporation of FITC-cadaverine on the microtubule structure. Samples were also observed in the rhodamine channel to prove that filamentous structures were definitely microtubules and in the FITC channel to visualize the incorporation of cadaverine.

\section{Binding assay of kinesin to TGase-treated microtubules}

Kinesin from Cytoskeleton (code number KR01, $0.1 \mathrm{mg} / \mathrm{ml}$ ) was added to microtubules (treated and untreated with pollen TGase) prepared as described above. After incubation for $30 \mathrm{~min}$ at $25^{\circ} \mathrm{C}$, samples were centrifuged at $15000 \mathrm{~g}$ for $1 \mathrm{~h}$ at $25^{\circ} \mathrm{C}$. Supernatants were prepared for SDS/PAGE. Pellets were washed with ATP buffer (80 mM Pipes, pH 6.8, 7 mM EGTA, 1 mM MgCl $2,1 \mathrm{mM}$ DTT, $20 \mu \mathrm{M}$ taxol and $10 \mathrm{mM}$ ATP); parts of the pellets were prepared for electrophoresis and the remaining part was incubated for $30 \mathrm{~min}$ at room temperature. Samples were centrifuged at $15000 \mathrm{~g}$ for $1 \mathrm{~h}$ at $25^{\circ} \mathrm{C}$ and then prepared for electrophoresis.

\section{In vitro motility assays}

Kinesin solution $(10 \mu \mathrm{l})$ from Cytoskeleton $(0.1 \mathrm{mg} / \mathrm{ml})$ was incubated for $5 \mathrm{~min}$ in perfusion chambers. Microtubules (treated or untreated with pollen TGase) were diluted 1:5 with motility buffer (80 mM Hepes, pH 7.5, 7 mM EGTA, $1 \mathrm{mM} \mathrm{MgCl} 2,1 \mathrm{mM}$ DTT, $20 \mu \mathrm{M}$ taxol and $5 \mathrm{mM}$ ATP). Then, $10 \mu \mathrm{l}$ of microtubule solution was incubated for $1 \mathrm{~min}$ in the perfusion chamber. Samples were observed at the optical microscope under DIC view. Motility of microtubules was recorded according to the literature [28].

\section{Incorporation of putrescine in TGase-treated microtubules}

Tubulin and microtubules were prepared as described above and adjusted at the concentration of $5 \mathrm{mg} / \mathrm{ml}$. Pollen TGase was added to the ratio of $1: 10$ with tubulin supplemented with $7 \mathrm{mM} \mathrm{CaCl}_{2}$ and 0.1 or $1 \mathrm{mM}$ putrescine. Samples were incubated at $37^{\circ} \mathrm{C}$ for $3 \mathrm{~h}$ and then observed with DIC microscopy. The enzyme reaction was stopped by addition of $7 \mathrm{mM}$ EGTA. Samples were centrifuged at $15000 \mathrm{~g}$ for $1 \mathrm{~h}$ at $25^{\circ} \mathrm{C}$. Supernatants and pellets were prepared for SDS/PAGE.

\section{Electrophoresis and immunoblot}

Electrophoresis of proteins was performed according to Laemmli [29]. Molecular mass standards were from Sigma-Aldrich or from Bio-Rad (Precision series). Gels were stained with BioSafe Coomassie Blue (Bio-Rad). Immunoblot was performed according to Towbin et al. [30]. Secondary antibodies against mouse and rabbit IgG were conjugated with horseradish peroxidase (GE HealthCare); secondary antibody to donkey IgG was conjugated with horseradish peroxidase (Cytoskeleton Inc.). 

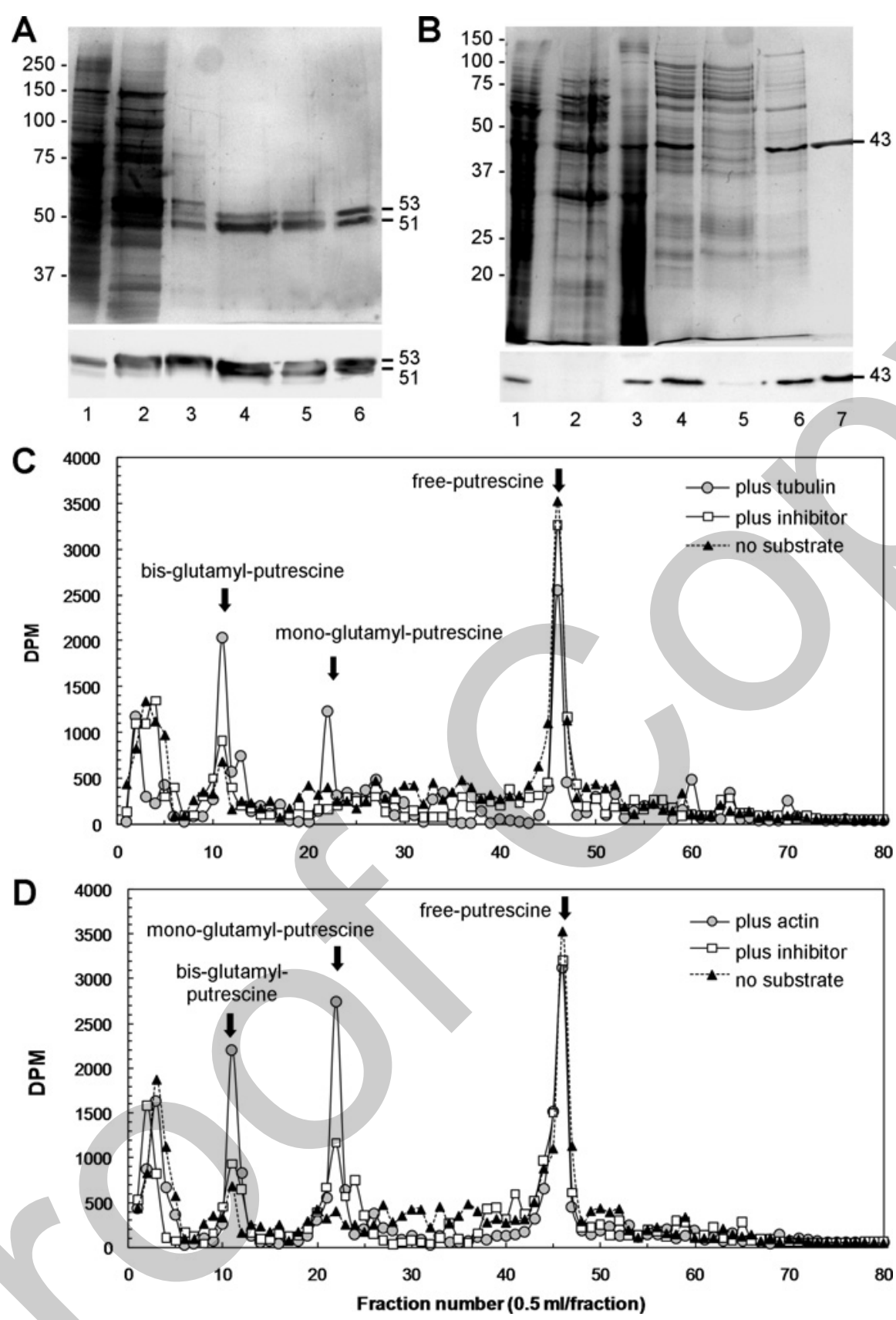

Figure 2 Purification of tubulin and actin from apple pollen and assay of pollen TGase

(A) SDS/PAGE illustrating the main steps of tubulin purification. Molecular mass standards are on the left; lane 1, pollen extract (20 $\mu \mathrm{g}$ ); lane 2, pool after Resource-Q column (20 $\mu \mathrm{g}$ ); lane 3 , pool after Sephacryl S-300 column; lane 4, pool after Mini-Q column; lane 5, supernatant after taxol polymerization; lane 6, pellet after taxol polymerization (lanes 3-6 contain $5 \mu \mathrm{g}$ of protein). The gel is Coomassie Blue-stained. Bottom panel: blot with anti-tubulin antibody. (B) Gel showing the main steps of actin purification. Molecular mass standards are on the left; lane 1, pollen extract $(20 \mu \mathrm{g})$; lane 2, proteins that do not sediment (15 $\mu \mathrm{g})$; lane 3, proteins that precipitate with $\left(\mathrm{NH}_{4}\right) \mathrm{SO}_{3}(15 \mu \mathrm{g})$; lane 4, pool after Mono-Q column (10 $\left.\mu \mathrm{g}\right)$; lane 5, proteins that do not polymerize; lane 6, proteins that polymerize and sediment with $\mathrm{MgCl}_{2}$; lane 7, pool after Superdex 200 column. Lanes 5-7 contain $5 \mu \mathrm{g}$ of protein. The gel is Coomassie Blue-stained. Bottom panel: blot with anti-actin antibody. (C and $\mathbf{D})$ Distribution of radioactivity in the TGase assay products performed by incubating the pollen TGase active fraction with [ $\left.{ }^{3} \mathrm{H}\right]$-putrescine, in the presence/absence of TGase inhibitor and pollen tubulin (C) or pollen actin (D). Arrows indicate standard retention times for bis- $\gamma$-glutamyl-putrescine and mono- $\gamma$-glutamyl-putrescine.

Immunoreactive bands were detected with $\mathrm{ECL}^{\circledR}$ (enhanced chemiluminescence) Plus reagents from GE Healthcare.

\section{Protein assay}

The protein content was determined using a modified bicinchoninic acid method [31]. BSA was used as the standard protein.

\section{RESULTS}

\section{Isolation and characterization of a TGase-enriched fraction from apple pollen}

A TGase activity-enriched fraction from apple pollen was eluted by HIC with $10 \mathrm{mM}$ EGTA (Figure 1A) and contained a prominent band at $70 \mathrm{kDa}$ (Figure 1B, lane 1), which catalysed transamidating reactions (see below). The EGTA-eluted fractions were 
enriched in TGase activity approx. 10-fold as shown by comparison with the HIC-unfractionated sample (Figure 1A). The $70 \mathrm{kDa}$ polypeptide cross-reacted with two monoclonal TGase antibodies, ID10 and AbIII (Figure 1B, lanes 2-3). The crossreactivity of ID10 was also evaluated on gplTGase and apple pollen extracts (lanes 4-5), while AbIII was tested on pollen extract (lane 6). Both antibodies cross-reacted with the $70 \mathrm{kDa}$ band in pollen extracts.

\section{Incorporation of polyamines in apple tubulin and actin}

To assess the enzyme activity of pollen TGase on tubulin and actin, the latter two proteins were first isolated from apple pollen. Tubulin was purified by chromatography (Figure 2A, top panel), yielding about $150 \mu \mathrm{g}$ of homogeneous tubulin (lane 4). After treatment with taxol, the protein was mostly found in the pellet (lane 6) and partly in the supernatant (lane 5), indicating that apple tubulin was competent of forming microtubules. The position of tubulin was monitored using a specific antibody (Figure 2A, lower panel).

Actin was isolated by precipitation with $\left(\mathrm{NH}_{4}\right)_{2} \mathrm{SO}_{4}$ and by chromatography. Approx. $250 \mu \mathrm{g}$ of actin was purified to homogeneity from apple pollen (Figure $2 \mathrm{~B}$, upper panel). After the Mono-Q step (lane 4), actin was still contaminated by additional proteins, whose level was reduced by the polymerization/depolymerization step (lane 5 and 6). The use of Superdex 200 column greatly enhanced the purity of actin (lane 7). Actin was monitored with a specific antibody (Figure 2B, lower panel). Figures 2(C) and 2(D) show the elution profiles of the digested trichloroacetic acid-insoluble fractions of apple tubulin (Figure 2C) and actin (Figure 2D) after incubation with the pollen TGase activityenriched fraction and $\left[{ }^{3} \mathrm{H}\right]$-putrescine. Incubation of tubulin and actin with $0.1 \mathrm{mM}$ putrescine led to the recovery of bis- $(\gamma$ glutamyl)-putrescine and mono-( $\gamma$-glutamyl $)$ derivatives, the free putrescine being internal standard. Presence of the TGase inhibitor 1,3-dimethyl-2-[(2-oxopropyl)thio] imidazolium chloride in the assay drastically reduced the formation of $\gamma$-glutamyl-putrescine, whereas the absence of the TGase substrates (tubulin and actin) did not allow the production of derivatives.

\section{Effects of pollen TGase on actin filaments}

Because mammalian actin/tubulin reacted with pollen TGase comparably with pollen actin/tubulin and because of their availability in larger quantities, rabbit muscle actin and bovine brain tubulin were used in all subsequent assays. The effects of pollen TGase on actin filaments was first investigated by analysing the sedimentation properties of in vitro polymerized actin (Figure 3 ). Pollen TGase (Figure 3A, lane 1, arrow) and FITC-cadaverine were incubated with filamentous actin (Figure 3A, lane 3) polymerized from rabbit G-actin (Figure 3A, lane 2). As control, F-actin was also examined in the absence of pollen TGase (Figure 3A, lane 4) but in the presence of FITC-cadaverine. The supernatant obtained in the presence of pollen TGase contained a small amount of actin (Figure 3A, lane 5), whereas the corresponding pellet showed the presence of large amounts of actin in addition to high-molecular-mass bands (Figure 3A, lane 6, arrowheads) showing molecular masses of 93, 133 and $155 \mathrm{kDa}$. The volumetric measure of those bands indicated that the ratio was $6: 4: 1$. In the absence of pollen TGase, the supernatant (Figure 3A, lane 7) contained only a small amount of actin, and the corresponding pellet (Figure 3A, lane 8) did not reveal the presence of additional bands other than actin. An actin antibody (Figure 3B) reacted with actin at $43 \mathrm{kDa}$, but also with the high molecular mass polypeptides (Figure 3B, lane 6). When fractions

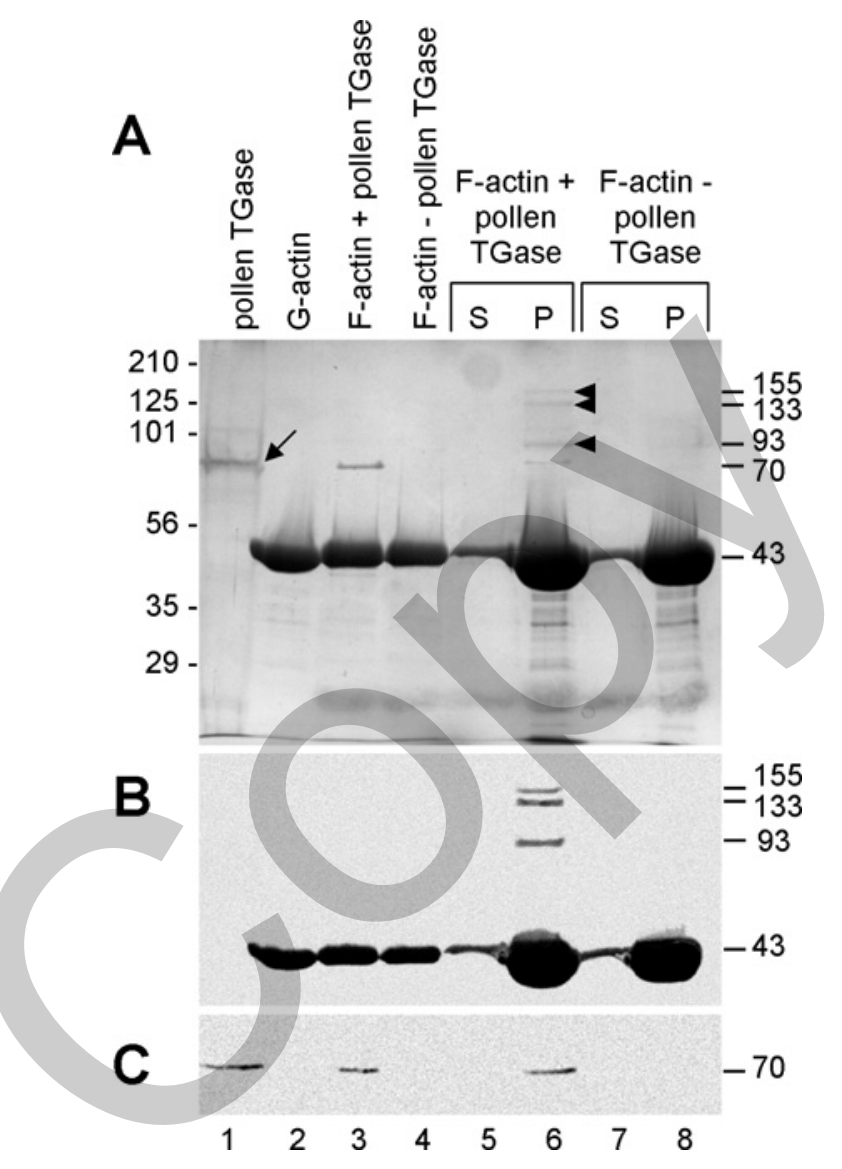

Figure 3 Enzyme activity of pollen TGase on F-actin

(A) Enzyme assay in the presence/absence of pollen TGase and FITC-cadaverine. Lane 1, pollen TGase (1 $\mu \mathrm{g}$, arrow); lane 2, monomeric actin (10 $\mu \mathrm{g})$; lane 3, filamentous actin (10 $\mu \mathrm{g}$ ) plus pollen TGase; lane 4, control of F-actin without pollen TGase $(10 \mu \mathrm{g})$. Lane 5 , supernatant in the presence of pollen TGase; lane 6, corresponding pellet; lane 7, supernatant in the absence of pollen TGase; lane 8, corresponding pellet. Arrowheads indicate high molecular mass polypeptides appearing in the presence of pollen TGase and cross-reacting with the anti-actin antibody. Protein content of lane 5-8 is 3-fold (30 $\mu \mathrm{g}$ ) higher than that of lanes 3-4 to show the high molecular mass aggregates. The gel is Coomassie Blue-stained. (B) Western blot with anti-actin antibody on fractions shown in (A). (C) Western blot with ID-10 on fractions shown in $(\mathbf{A})$.

were tested with the ID10 antibody in Figure 3(C), the pollen TGase was found in lane 1 (containing the enzyme only), in lane 3 (enzyme plus actin) and in the sample containing the actin-related high molecular mass aggregates (Figure 3C, lane 6). The pollen TGase was not found in the high molecular mass aggregates. As control, the same assay performed with gplTGase and FITCcadaverine yielded results similar to those obtained with pollen TGase (Supplementary Figure S1 at http://www.BiochemJ.org/ bj/418/bj418ppppadd.htm).

To demonstrate that FITC-cadaverine bound to actin filaments, the pellet obtained in the presence/absence of pollen TGase was observed under fluorescence microscopy in the rhodamine channel (for visualizing actin) and in the FITC channel (for visualizing FITC-cadaverine). The sample in lane 6 of Figure 3(A) showed the presence of a conspicuous network of actin filaments (Figure 4A), which was also detected in the FITCchannel (Figure 4B). In the absence of pollen TGase (lane 8 of Figure $3 \mathrm{~A}$ ), we still observed the network of fluorescent actin filaments (Figure 4C), but no signal was detected in the FITC channel (Figure 4D), apart from random bright spots. This result indicated that FITC-cadaverine did not bind to actin in the absence 

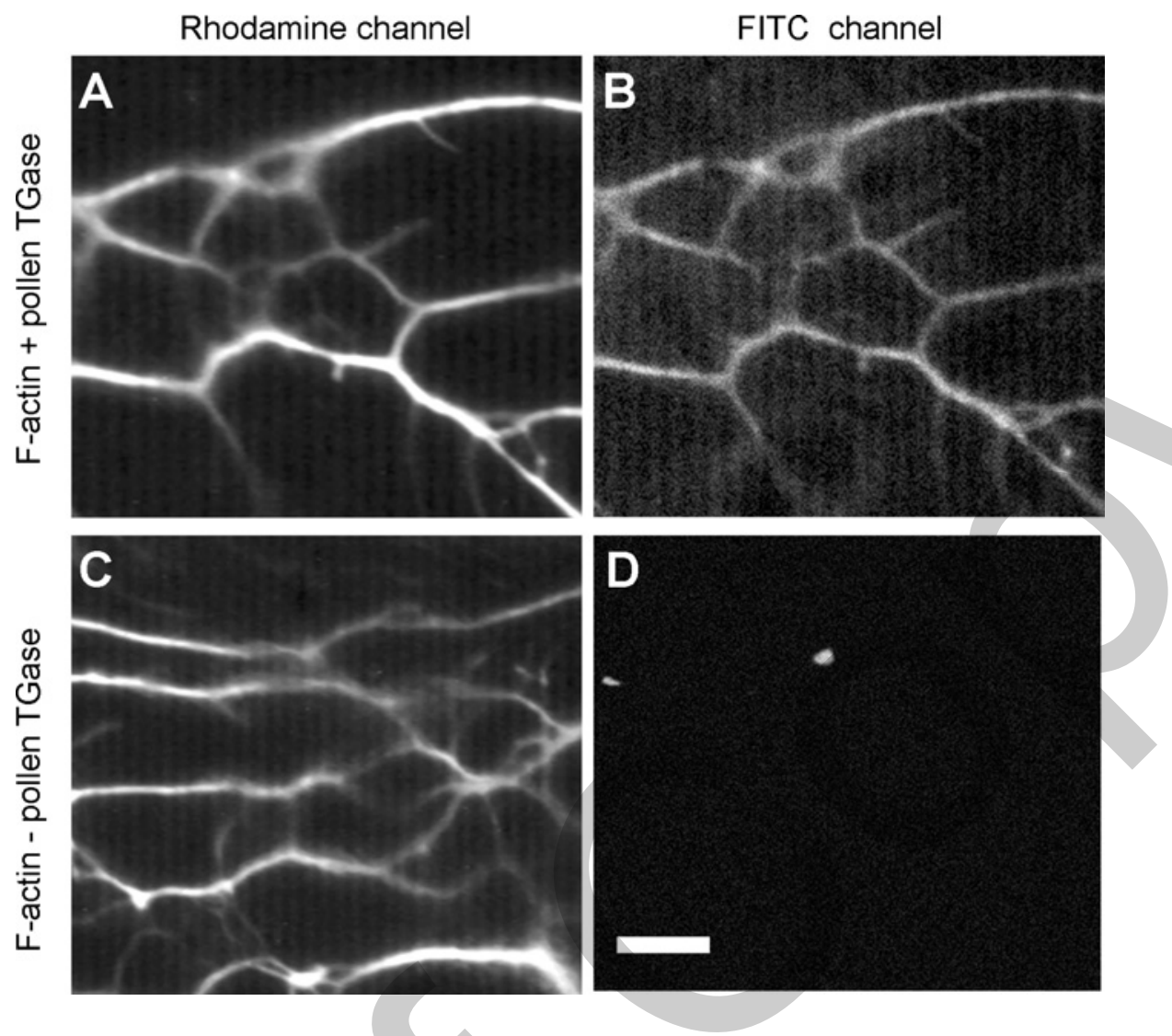

Figure 4 Incorporation of FITC-cadaverine in rabbit actin by pollen TGase

(A) F-actin after incorporation of FITC-labelled cadaverine in the presence of pollen TGase as observed in the rhodamine filter. (B) Same field observed in the FITC filter set. (C) Rhodamine-labelled F-actin obtained in the absence of pollen TGase as observed in the related filter set. (D) Same view field observed in the FITC filter set. Scale bar: $2 \mu \mathrm{m}$.

of pollen TGase. The control in the presence of gplTGase was almost comparable with that of pollen TGase (Supplementary Figure S2 at http://www.BiochemJ.org/bj/418/bj418ppppadd.htm).

We also analysed the enzyme activity of myosin and its binding to actin filaments. First, the ATPase activity of rabbit myosin was tested in the presence of different concentrations of F-actin $(10,20$ and $50 \mu \mathrm{g} / \mathrm{ml})$, pre-treated (+ TGase) and untreated with either pollen or gplTGase (Figure 5A). Actin alone showed no significant ATPase activity, as well as actin in combination with either pollen TGase or gplTGase. The ATPase activity of myosin alone was slightly detectable. In the absence of TGase, the ATPase activity of myosin increased following the different concentrations of actin. An increasing trend was also observed with TGase-treated actin; however, the increase of ATPase activity was greatly reduced when compared to untreated actin.

To visualize the binding of myosin to actin, we used a sedimentation assay. In the absence of pollen TGase (Figure 5B), myosin bound almost completely to actin filaments (lane 2) and was not found in the supernatant (lane 1). When pollen TGase-treated actin was used, part of myosin (around $40 \%$ ) was recovered in the supernatant (lane 3 ) and the remaining $60 \%$ in the pellet (lane 4). A comparable result was obtained with gplTGase (Supplementary Figure S3 at http://www.BiochemJ.org/bj/418/ bj418ppppadd.htm).

\section{Effects of pollen TGase on microtubules}

We also analysed the effects of pollen TGase on the assembly/ disassembly of microtubules at different temperatures. Pollen
TGase (Figure 6A, lane 2) was mixed with rhodamine-labelled or unlabelled tubulin (lane 3), which was polymerized at $37^{\circ} \mathrm{C}$ in the presence of FITC-cadaverine. In the absence of TGase, tubulin was partly found in the supernatant S1 (approx. 30\%, lane 4) but more consistently in the pellet P1 (approx. 70\%, lane 5). When $\mathrm{Ca}^{2+}$-free buffers were used (80 mM Pipes, pH 6.8, $1 \mathrm{mM}$ $\mathrm{MgCl}_{2}$ and $1 \mathrm{mM}$ EGTA), the percentage of tubulin in the pellet increased to $90 \%$ (results not shown). Around $55 \%$ of pollen TGase-treated tubulin was found in the supernatant S1 (lane 6), whereas the corresponding pellet P1 contained $45 \%$ of initial tubulin and additional high molecular mass bands (arrowheads) at $106,121,143$ and $165 \mathrm{kDa}$ (the latter being the most abundant), plus a very heavy band in the gel top. When the pellets of lanes 5 and 7 were depolymerized, the TGase-untreated sample yielded a supernatant (S2, lane 8) enriched in tubulin, approx. $73 \%$ of total tubulin compared with the pellet P2 (lane 9). When TGase-treated tubulin was depolymerized, the supernatant S2 (lane 10) contained low levels of tubulin ( $32 \%$ of total tubulin) in comparison with the pellet P2 (lane 11); the pellet also contained the high molecular mass aggregates (arrowheads). Presence of tubulin in the high molecular mass aggregates was shown by immunoblot with the tubulin antibody (Figure 6B). Pollen TGase was detected by immunoblot in the tubulin pellet containing the high molecular mass aggregates (Figure 6B, lane 7). Although the pollen TGase remained in the $\mathrm{P} 2$ pellet after depolymerization (Figure 7B, lane 11 ), it was not found in association with the high molecular mass aggregates.

The microtubule pellets of lane 5 and 7 in Figure 6A were observed with DIC microscopy. TGase-treated microtubules were 

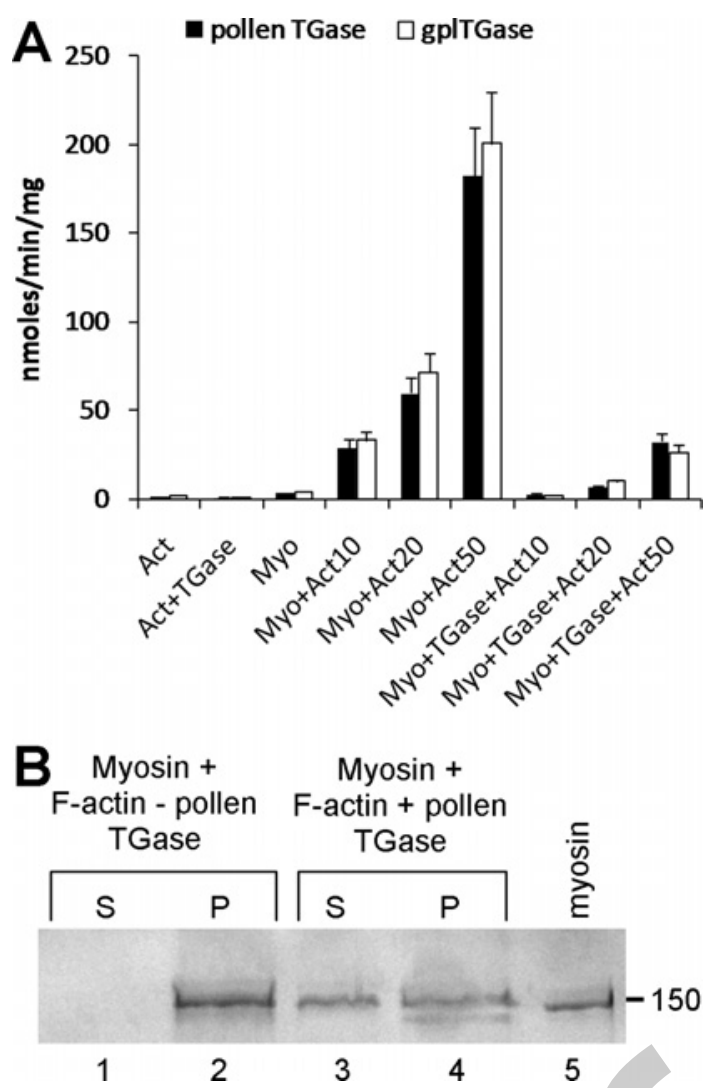

Figure 5 Enzyme activity and binding assay of myosin in the presence/absence of pollen TGase and FITC-cadaverine

(A) Enzyme activity of myosin in the presence of different concentrations of F-actin after incubation with either pollen TGase or gplTGase. In the absence of TGase, the activity of myosin is always higher than the corresponding activity in the presence of either pollen TGase or gplTGase. For comparison, the enzyme activity of actin (Act), actin and TGase (Act + TGase) and myosin (Myo) alone were also tested. All values are means \pm S.E.M. for $n=3$ separate determinations. (B) Binding assay of myosin to actin filaments after incubation with pollen TGase. Lane 1 and 3 are supernatants after binding assay in the absence or presence of pollen TGase respectively. Lane 2 and 4 are the corresponding pellets. Total protein $(6 \mu \mathrm{g})$ was loaded in each lane; the myosin band approximately corresponded to $1 \mu \mathrm{g}$. Lane 5 is rabbit myosin $(1 \mu \mathrm{g})$. The gel is Coomassie Blue-stained.

observed as bundles from which single microtubules radiated (Figure 6D, left panel). Identity of microtubules was confirmed by fluorescence microscopy in the rhodamine channel (Figure 6D, central panel). The co-distribution of FITC-cadaverine with microtubules was evaluated in the FITC channel (Figure 6D, right panel). As control, the pellet of lane 5 (TGase-untreated microtubules) was observed as single filaments, but not as bundles (Figure 6E). When unlabelled tubulin was used, fluorescence in the rhodamine channel was not detected, but it was in the FITC channel.

We investigated the effects of TGase and FITC-cadaverine on the binding of kinesin to microtubules. Tubulin (Figure 7A, lane 2) was polymerized into microtubules (Figure 7A, lane 4) in the presence of pollen TGase (Figure 7A, lane 3) and the mixture (Figure 7A, lane 5) was used for the binding assays. In controls, nearly all of kinesin pelleted with untreated microtubules (Figure 7A, lane 7) comparing with the corresponding supernatant (Figure 7A, lane 6). When the pellet was washed with ATP (Figure 7A, release step), kinesin was found essentially in the supernatant (Figure 7A, lane 9) but not in the pellet (Figure 7A, lane 8). Kinesin bound only partially (approx. 60\%) to TGase-treated- microtubules (Figure 7A, lane 11), compared with soluble kinesin (Figure 7A, lane 10, approx. $40 \%$ ). After the ATP-releasing step, all kinesin was found in the supernatant (Figure 7A, lane 13) and not in the microtubule pellet (Figure 7A, lane 12). Pollen TGase was immunostained with ID10 (Figure 7B).

The effect of pollen TGase on the kinesin-mediated microtubule motility was analysed by in vitro gliding assay. In the control (Figure 8A), untreated microtubules (arrows and arrowheads) moved with a speed of 0.4 to $0.6 \mu \mathrm{m} / \mathrm{sec}$ on kinesin-coated glass slides. The mean velocity of TGase-treated microtubules was significantly lower $(0.2-0.3 \mu \mathrm{m} / \mathrm{sec}$, Figure $8 \mathrm{~B})$ and we frequently observed presumptive microtubule bundles (black arrowhead) moving along kinesin-coated slides.

The ability of pollen TGase to form polyamine-mediated bridges between tubulin molecules was tested by mixing tubulin with pollen TGase and putrescine (Figure 9). Bovine brain tubulin (Figure 9A, lane 1) was polymerized in the presence of pollen TGase (Figure 9A, lane 2) and either 0.1 or $1 \mathrm{mM}$ putrescine and centrifuged. In the absence of putrescine, the supernatant (Figure 9A, lane 3) contained small amounts of tubulin, whereas the pellet (Figure 9A, lane 4) showed high molecular mass aggregates (arrowheads) at 97, 106, 150 (the most abundant) and $258 \mathrm{kDa}$. In the presence of $1 \mathrm{mM}$ putrescine, the supernatant contained only tubulin monomers (Figure 9A, lane 5), whereas the corresponding pellet showed larger amounts of the high molecular mass aggregates (Figure 9A, lane 6). When pollen TGase was omitted, the supernatant (Figure 9A, lane 7) showed essentially tubulin monomers, whereas the corresponding pellet (Figure 9A, lane 8) contained tubulin but not additional high molecular mass aggregates. Using DIC microscopy, the microtubule pellet of lane 4 (Figure 9A) showed the previously described bundles of microtubules (Figure 9B). Microtubules in the presence of pollen TGase and $1 \mathrm{mM}$ putrescine (lane 6 of Figure 9A) appeared as amorphous structures without the typical filamentous aspect of microtubules (Figure 9C). When microtubules were incubated with putrescine but without TGase (lane 8 of Figure 9A), they were indistinguishable from untreated microtubules (results not shown). The same experiment was performed in the presence of $0.1 \mathrm{mM}$ putrescine (Figure 9D). Arrows indicate the presence of lower amounts of high molecular mass aggregates. Using DIC microscopy, microtubules treated with TGase in the absence of putrescine (lane 6 in Figure 9D) appeared as bundles (Figure 9E). In contrast, the microtubule pellet after treatment with pollen TGase and $0.1 \mathrm{mM}$ putrescine (lane 4 in Figure 9D) showed the presence of aberrant microtubule structures (Figure 9F).

\section{DISCUSSION}

Using the $\mathrm{Ca}^{2+}$-binding property of TGases, a $70 \mathrm{kDa}$ polypeptide was identified in apple pollen extracts (Figure 1B), which showed molecular and immunological characteristics very similar to those of the well known TGase-2, which is widely expressed in many animal cells. The pollen protein shared typical functions of TGases, as shown by its capacity to catalyse the formation of glutamyl-polyamine derivatives, by its inhibition with a sitedirected TGase inhibitor and by the comparative analysis of its products (Figures 2C and 2D). The pollen TGase recognized actin and tubulin, catalysing the formation of high molecular mass aggregates (Figures 3A and 6A). In addition, pollen TGase influenced the binding of myosin and kinesin to actin filaments (Figure 5B) and microtubules (Figure 7) respectively. Pollen TGase can also reduce the enzyme activity of myosin (Figure 5A) and the gliding activity of kinesin (Figure $8 \mathrm{~B}$ ). Taken together, 


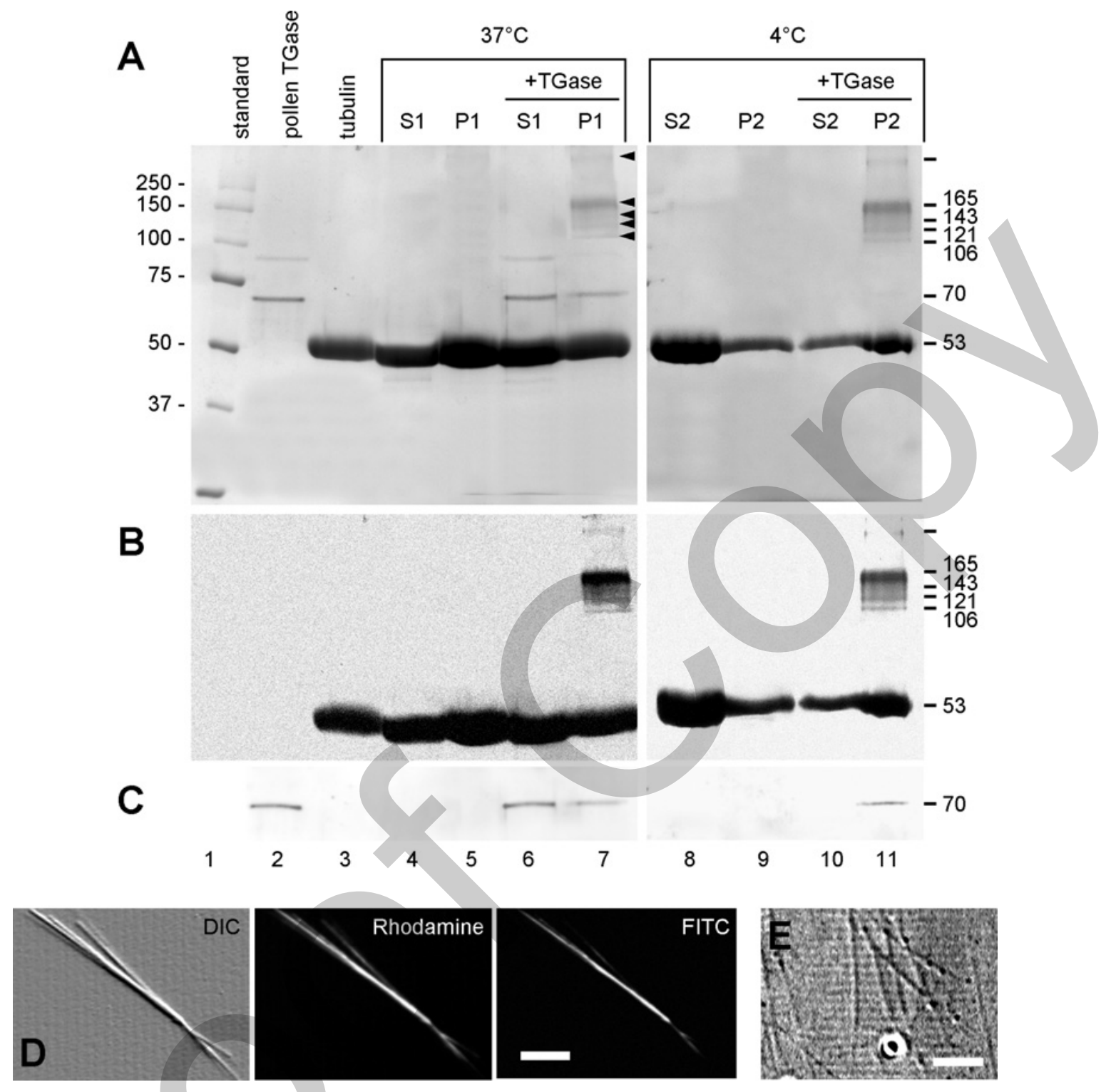

Figure 6 Tubulin polymerization/depolymerization assay in the presence/absence of pollen TGase and FITC-cadaverine

(A) Coomassie Blue-stained gel showing the main fractions obtained in the assay. Lane 1, molecular mass standards in kDa. Lane 2, pollen TGase (1 $\mu$ g). Lane 3, bovine brain tubulin. Lane 4 supernatant (S1) after polymerization of tubulin at $37^{\circ} \mathrm{C}$ in the absence of TGase. Lane 5 , corresponding pellet (P1). Lane 6, supernatant (S1) after polymerization of tubulin at $37^{\circ} \mathrm{C}$ in the presence of TGase. Lane 7, corresponding pellet (P1). Arrowheads indicate the high molecular mass polypeptides in the microtubule pellet after incubation of tubulin with pollen TGase. Lane 8, supernatant (S2) after depolymerization of the microtubule pellet of lane 5. Lane 9, the corresponding pellet (P2). Lane 10, supernatant (S2) after depolymerization of the microtubule pellet of lane 7. Lane 11, the corresponding pellet (P2). Arrowheads indicate the high molecular mass aggregates already found in P1. Lanes 3-11 contain $10 \mu \mathrm{g}$ of protein. (B) Western blot with the anti-tubulin antibody on the same fractions shown in (A). (C) Western blot with ID10 antibody on the same samples shown in (A). (D) Visualization of rhodamine-stained microtubules after treatment with pollen TGase The pellet in lane 7 was observed with DIC microscopy (left panel), with fluorescent microscopy in the rhodamine filter (central panel) and in the FITC filter (right panel). (E) Visualization of the microtubule pellet from lane 5. Scale bars: $4 \mu \mathrm{m}$.

these findings showed that pollen TGase potentially acts as regulator of the cytoskeleton activity in pollen tubes.

\section{Pollen TGase induces the formation of high molecular mass aggregates of actin}

Regulation of actin filament dynamics by post-translational modifications is poorly documented in plant cells. Evidence that actin is substrate of the partially purified $70 \mathrm{kDa}$ pollen TGase (Figures 2D and 3A) is in agreement with preliminary data showing that pollen actin was modified with polyamines after incubation with apple pollen crude extracts [18] to produce actin aggregates similar to those catalysed by TGase from bacteria [32], animals and Physarum polycephalum [15]. In animals the formation of aggregates was attributed to intermolecular (and intramolecular) linkages by Gln-Lys cross-links. The intermolecular bond between $\operatorname{Gln}^{41}$ and Lys ${ }^{113}$ observed by linking ANP [N-(4-azido-2-nitrophenyl)-putrescine] makes G-actin more resistant towards proteolytic degradation and reduces the depolymerization of F-actin [33]. In addition, the occurrence of intramolecular cross-linking between $\mathrm{Gln}^{41}$ and $\mathrm{Lys}^{50}$ in rabbit muscle actin was followed by stabilization of F-actin structure [32]. Reports on animal or bacterial TGases indicated that Gln ${ }^{41}$ 


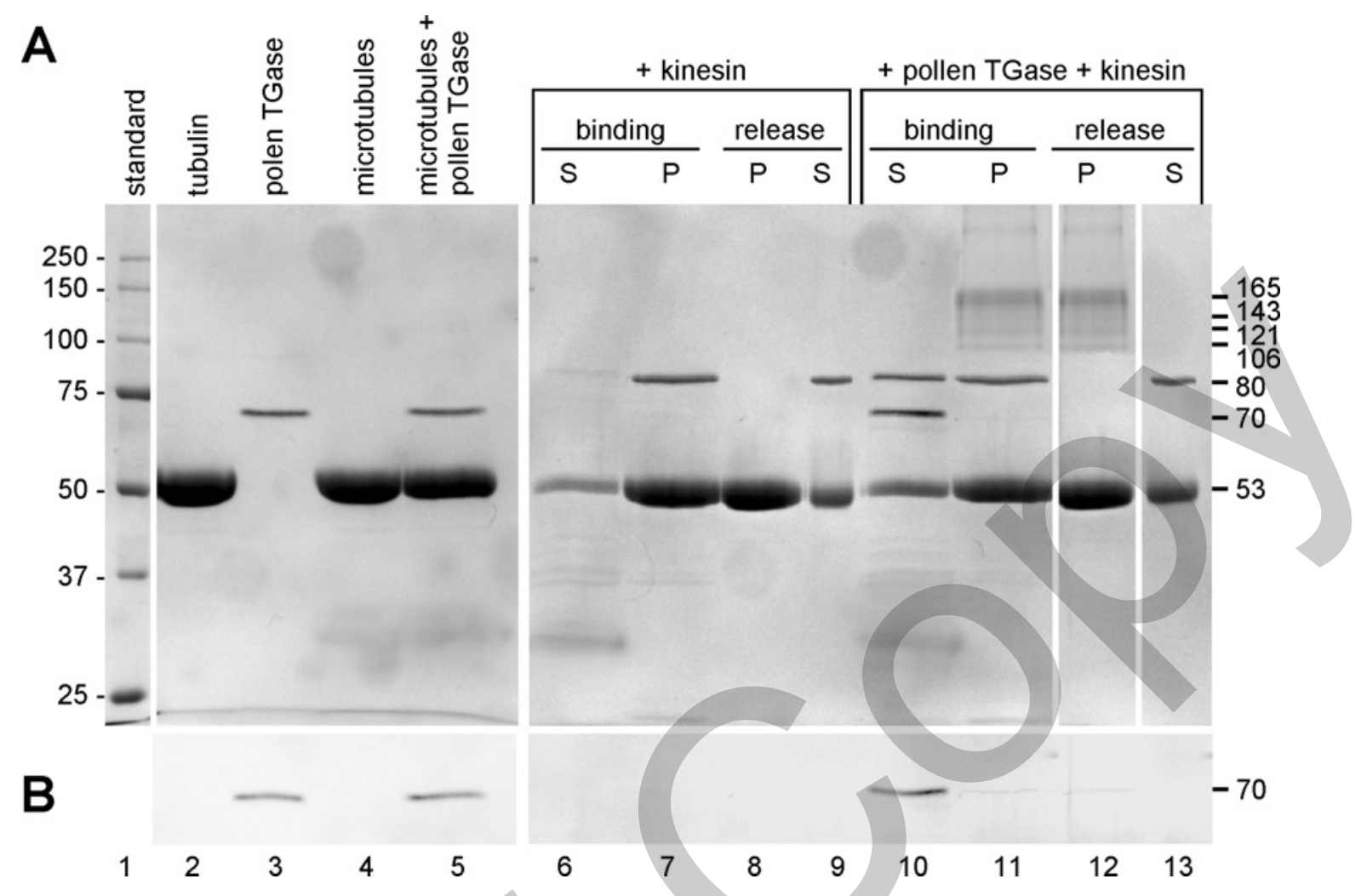

Figure 7 Binding assay of kinesin to microtubules in the presence of pollen TGase and FITC-cadaverine

(A) Coomassie Blue-stained gel showing the main fractions obtained during the binding and releasing of kinesin. Lane 1, molecular mass standards (values shown to the left in $\mathrm{kDa}$ ). Lane 2 , tubulin $(10 \mu \mathrm{g})$. Lane 3, pollen TGase $(1 \mu \mathrm{g})$. Lane 4, microtubules $(10 \mu \mathrm{g})$. Lane 5, a mixture of microtubules and pollen TGase $(10 \mu \mathrm{g})$. Lane 6 , supernatant (S) after binding of kinesin to TGase-untreated microtubules. Lane 7, corresponding pellet (P). Lane 8, pellet after ATP-release of kinesin. Lane 9, corresponding supernatant. Lane 10, supernatant after binding of kinesin to TGase-treated microtubules. Lane 11, corresponding pellet. Lane 12, pellet after ATP-release of kinesin. Lane 13, corresponding supernatant. Protein content in pellet samples of lanes 2, 4, 5 and 6-13 was $10 \mu \mathrm{g}$, and the protein content of supernatants was not estimated because loaded volumes had to be identical to pellet samples. (B) Western blotting of samples shown in (A) with ID10.

is the only glutamine residue on actin that reacts with primary derivatized amines such as ANP [33] and dansyl-ethylenediammine [34] in the TGase-catalysed reaction [26] forming Gln-mono derivatives. In the present manuscript, the FITCcadaverine test (Figure 4) and the formation of radioactive monoputrescine via unmodified radiolabelled polyamines (Figures 2C and 2D) suggested that the pollen TGase has identical activity. When unmodified polyamines were conjugated, a role in addition to cationization of the free polyamine amino group in F-actin stabilization can be discussed. F-actin-like filaments are reversibly formed when G-actin was incubated with spermine and spermidine at relatively low concentrations in the absence of TGase. This reversible polymerization was attributed to the formation of ionic linkages with polyanionic regions at the $\mathrm{N}$-terminus of actin [35].

The formation of bis-putrescine derivatives by pollen TGase (Figures 2C and 2D) is a clear demonstration of cross-links between two glutamine residues. Assuming that $\mathrm{Gln}^{41}$ is the only residue modified by pollen TGase, the polyamine bis-derivatives should form intermolecular cross-linking between $\mathrm{Gln}^{41}$ of different monomers or filaments. A single polyamine molecule can thus use its two terminal amino-groups to form either reversible ionic or irreversible covalent linkages with actin, the latter being mediated by TGase. Either excessive concentrations of polyamine or its absence disturbs the correct polymerization of actin in the presence of TGase; moreover, unordered bundles of actin appeared at high concentrations, suggesting that the actin binding sites are possibly saturated, giving rise to many mono-polyamine derivatives instead of forming the correct site-specific cross-links by bis-derivatives [36]. The natural polyamine concentrations (estimated approx. $50 \mu \mathrm{M}$ in hydrated pollen) should decrease the competition for the protein-binding sites, allowing bis-derivatives to form, as it occurs with $100 \mu \mathrm{M}$ putrescine (the optimal concentration used for the in vitro TGase assay reported here).

\section{Pollen TGase affects the polymerization dynamic of microtubules}

TGases were shown to catalyse the conjugation of putrescine to tubulin in animal embryos, generating high molecular mass cross-linkage products [37] as also occurred in cells committed to apoptosis [38] and in the human placenta [16]. In plants, there are few studies on this topic; we previously showed that pollen tubulin was modified by polyamines after incubation with pollen crude extract, suggesting the occurrence of a catalysing TGase activity [18]. Present results showed that pollen TGase changed the polymerization rate of tubulin in the presence of polyamines (Figure 6). Given that pollen TGase was never found in the actin and tubulin aggregates, its binding to aggregates should be transient or relatively weak to be broken by SDS. At $37^{\circ} \mathrm{C}$, TGasetreated tubulin assembled to a small extent into microtubules and, simultaneously, formed high molecular mass aggregates. Temperature-dependent depolymerization is decreased, suggesting that the conjugation of polyamines generated more stable microtubules (Figure 6). When the protein aggregates from the cadaverine (one binding site) and putrescine (two binding sites) 

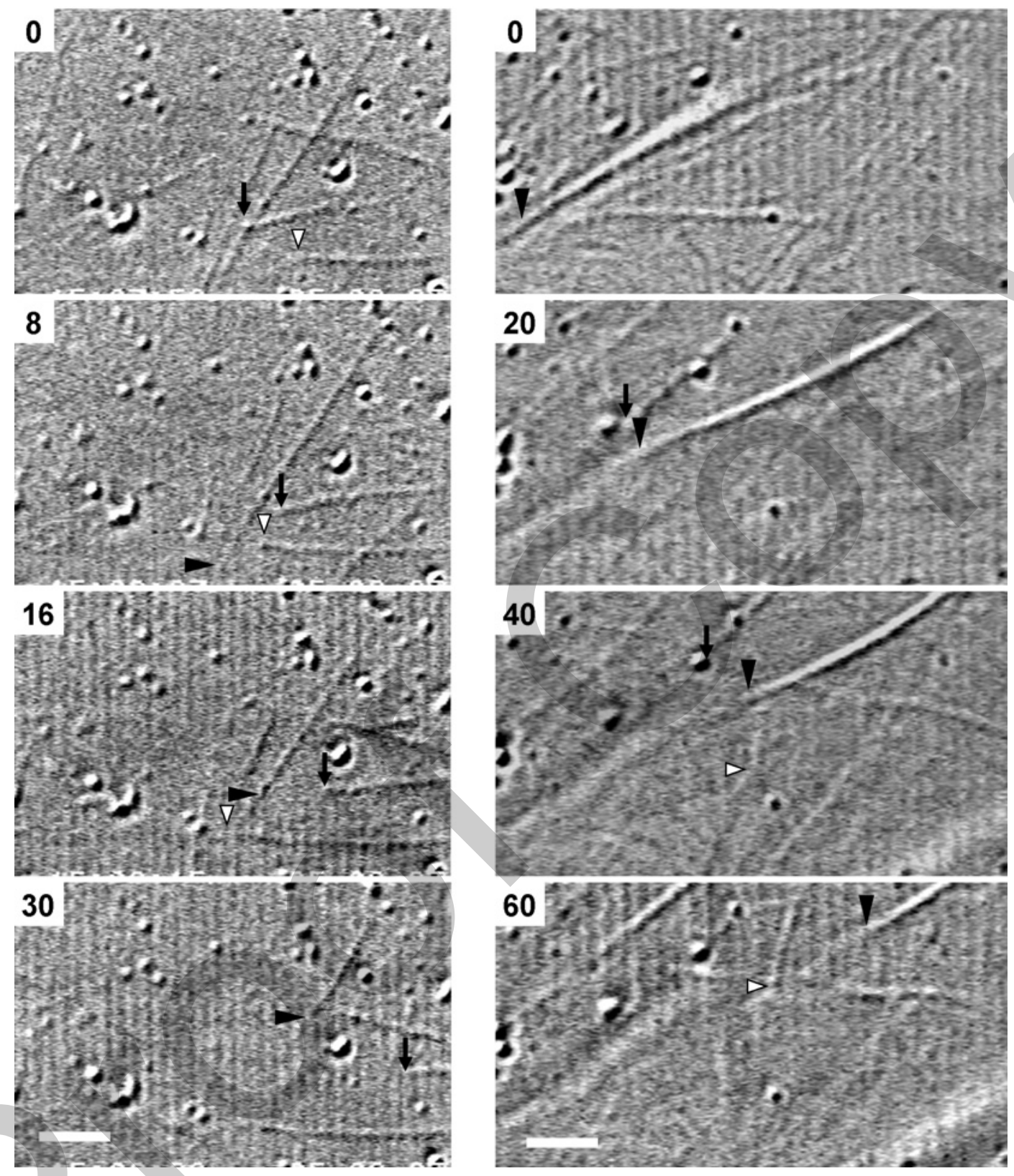

Figure 8 Motility assay of microtubules along kinesin-coated slides

(A) Untreated microtubules gliding over kinesin-coated slides. Microtubules move with speeds ranging from 0.4 to $0.6 \mu \mathrm{m} / \mathrm{sec}$. Arrows and arrowheads indicate some specific microtubules. Numbers in the top left corner are time in seconds. Scale bar: $5 \mu \mathrm{m}$. (B) TGase-treated microtubules moving along kinesin-coated slides. Microtubules move with speeds around 0.2-0.3 $\mu \mathrm{m} / \mathrm{sec}$. Arrows and arrowheads indicate moving microtubules. Black arrowhead indicates putatively one microtubule bundle. Numbers in the top left as in (A) corner are time in seconds. Scale bar: $3 \mu \mathrm{m}$.

assays were compared, some bands showed similar or identical molecular mass (i.e. $106 \mathrm{kDa}$ ); other aggregates appeared specific for the used polyamine, although the most abundant aggregates always showed a molecular mass around 150 to $160 \mathrm{kDa}$ (Figures 6 and 9). These aggregates are probably covalent dimers or trimers of tubulin produced by TGase activity. With DIC microscopy, the presence of relatively high concentrations (1 mM) of putrescine generated amorphous structures with no filamentous appearance was shown (Figure 9). On the contrary, presence of either the same concentration of FITC-cadaverine (having half available binding sites) or TGase only yielded filamentous structures (presumably microtubule bundles). Putrescine at lower concentration (closer to the presumptive natural one) generated either filamentous or amorphous microtubule structures (Figure 6D). A reasonable hypothesis is that pollen TGase formed monomer aggregates at $1 \mathrm{mM}$ putrescine concentration, which could slow down the polymerization rate of tubulin, thus explaining the low quantity of tubulin in the pellet. Rather than forming true microtubules, monomer aggregates could induce the formation of microtubule bundles, not necessarily formed only by covalent aggregates of tubulin but also by monomeric tubulin "entrapped" into the aggregates. 

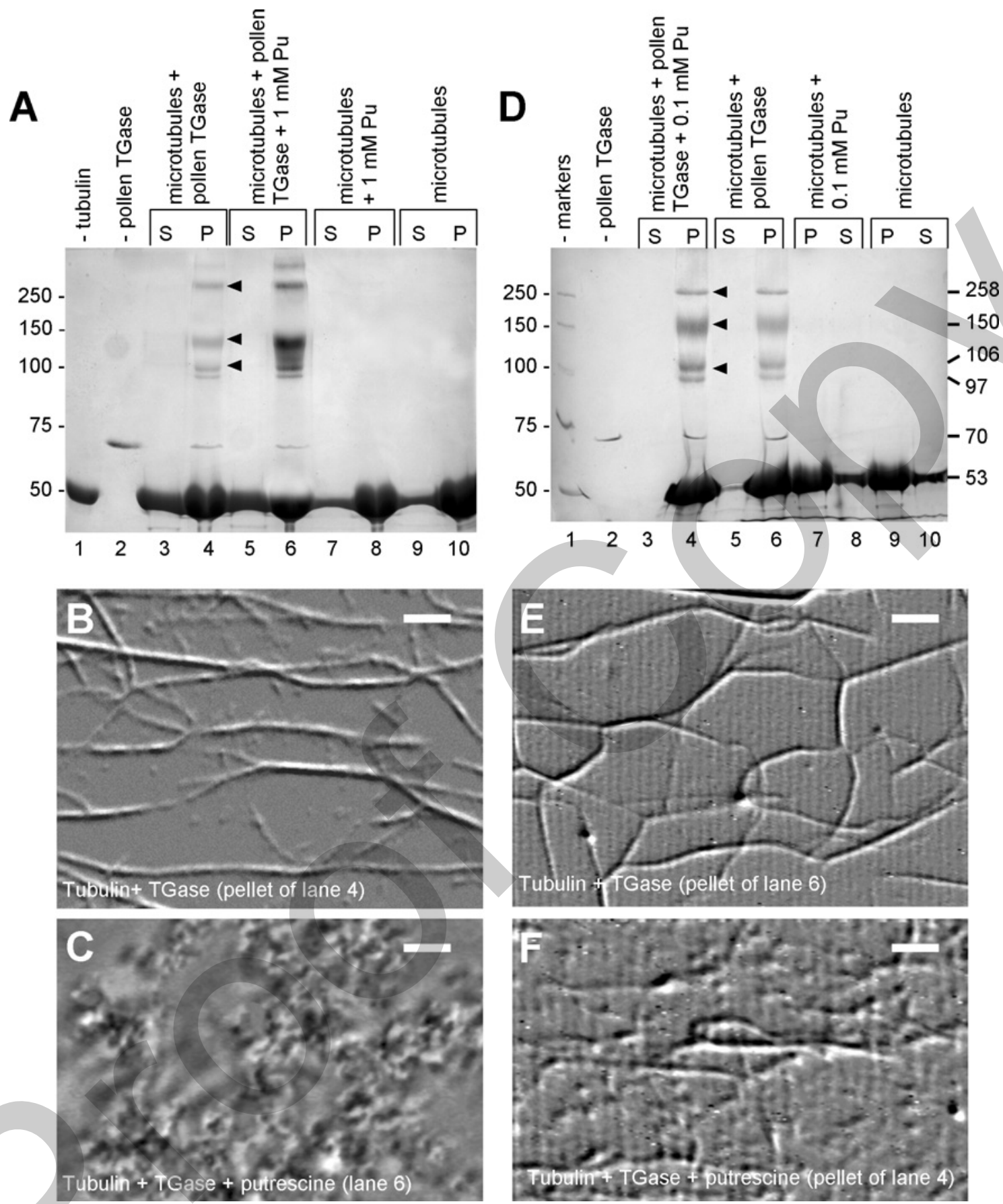

\section{Figure 9 Reactivity of microtubules with pollen TGase in the presence of putrescine}

(A) Effects of $1 \mathrm{mM}$ putrescine (Pu). Lane 1, microtubules $(10 \mu \mathrm{g})$. Lane 2, pollen TGase $(1 \mu \mathrm{g})$. Lane 3, supernatant after incubation of microtubules with pollen TGase. Lane 4, corresponding pellet; arrowheads indicate high molecular mass polypeptides. Lane 5, supernatant after incubation of microtubules with pollen TGase and $1 \mathrm{mM}$ putrescine. Lane 6, corresponding pellet; the high molecular mass aggregates are more visible. Lane 7, supernatant after incubation of microtubules with putrescine only. Lane 8, corresponding pellet. Lane 9 , supernatant after incubation of microtubules only. Lane 10, corresponding pellet. Protein content in pellet samples of lanes 3-10 was $30 \mu \mathrm{g}$, while the protein content of supernatants was not estimated because loaded volumes had to be identical to pellets. The gel is Coomassie Blue-stained. (B) DIC view of microtubules after TGase treatment (pellet in lane 4 of gel A). (C) Microtubules after treatment with pollen TGase and $1 \mathrm{mM}$ putrescine (pellet in lane 6 of gel $\mathbf{A}$ ). Scale bar for (B) and (C): $4 \mu \mathrm{m}$. (D) Effects of $0.1 \mathrm{mM}$ putrescine (Pu). Lanes contain samples equivalent to the gel in (A); protein content was also comparable. Arrows indicate the presence of high molecular mass aggregates. The gel is Coomassie Blue-stained. (E) Microtubules after TGase treatment (pellet of lane 6 in gel $\mathbf{D})$. (F) Microtubules after treatment with pollen TGase and $0.1 \mathrm{mM}$ putrescine (pellet of lane 4 in gel $\mathbf{D}$ ). Scale bar for $(\mathbf{E})$ and $(\mathbf{F}): 4 \mu \mathrm{m}$.

\section{Modification of actin and tubulin by pollen TGase influences the activity of myosin and kinesin}

Actin filaments treated with pollen TGase bound less efficiently to myosin and enhanced the ATPase activity of myosin to a small extent, suggesting that pollen TGase had effects on the overall activity of the acto-myosin system (Figures 5A and $5 \mathrm{~B})$. Our findings are therefore in agreement with data showing that the cross-linking between $\mathrm{Gln}^{41}$ and $\mathrm{Cys}^{374}$ on adjacent monomers of actin filaments inhibits the acto-myosin motility 
and force generation $[39,40]$. In addition, the TGase-mediated intramolecular cross-linking between $\mathrm{Gln}^{41}$ and $\mathrm{Lys}^{50}$ disturbed the structure of G-actin but apparently had small effects on actin polymerization and on myosin interaction [32] or could even activate the ATPase activity of myosin subfragment 1 [9]. Oriol-Audit [41] also reported that the polyamine-induced F-actin strongly triggered the $\mathrm{Mg}^{2+}$-ATPase activity of myosin.

In the present study, we showed that kinesin activity was reduced after polyamination of microtubules by pollen TGase. Specifically, kinesin bound with low affinity to TGase-modified microtubules but the ATP-releasing step was not affected (Figure 7A). The low binding affinity also reflected on the motor activity of kinesin; in vitro motility assays showed that TGasemodified microtubules moved with lower speed (at least $50 \%$ of reduction) compared with unmodified microtubules (Figures $8 \mathrm{~A}$ and $8 \mathrm{~B}$ ). These results confirm that pollen TGase can also act as a 'biological glue' because of its capacity to cross-link proteins and to reduce their movement ability. These results are in agreement with the evidence that the motor activity of kinesin is also regulated by post-translational modification of tubulin. Members of the kinesin subfamily Kif5c moved predominantly along stable microtubules, which are mainly composed of detyrosinated tubulin [42]. Other post-translational modifications that affected kinesinbased motility are glycylation, glutamylation and acetylation [43].

\section{Hypothesis on the role of TGase during pollen tube growth}

Results in the present paper suggested that the covalent cross-link of polyamines by pollen TGase generates stable actin aggregates, which alter the dynamic properties of actin filaments and the interaction of myosin with actin. Consequently, pollen TGase may participate in actin regulation during pollen tube growth. Since the proper organization of the actin cytoskeleton is essential for tube growth and organelle movement [2], any disorganization of the motor apparatus generates critical changes in organelle motility and pollen tube growth. Given that $\mathrm{Ca}^{2+}$ is an important regulatory factor of TGase activity [18], local variation of $\mathrm{Ca}^{2+}$ concentration in the pollen tube may regulate the protein conformation and its enzymatic activity. We hypothesize that pollen TGase controls the transition between actin bundles and short filaments at the boundary between the apical and base domains of pollen tubes [44], favouring the assembly of more stable bundles. TGase activity may also be regulated by $\mathrm{pH}$ changes. The optimum $\mathrm{pH}$ value of TGase is alkaline [45] and the presence of an alkaline band in pollen tubes [46] suggests that local variation in $\mathrm{pH}$ may trigger the TGase activity in these restricted areas. The polyamine concentration is also relevant by pushing toward the formation of mono- or bis-derivatives [18]. Consequently, the actin-actin interactions, the actin-mono-polyamine linking and the possible ionic bonds between the free amino groups of bound polyamines with other pollen molecules are finely regulated by the in vivo conditions of the pollen tube.

The results of the present study also suggested that the TGase-mediated conjugation of polyamines is part of the mechanism that regulates microtubule dynamic and functioning. In eukaryotic cells, the dynamic of microtubules is dependent on MAPs (microtubule-associated proteins), which are poorly known in pollen tubes; the exception is represented by a couple of polypeptides that enhance microtubule polymerization and possibly mediate the interaction of microtubules with the plasma membrane [47]. The functioning of pollen tube microtubules involves the control of vacuole positioning [48], the trafficking velocity of mitochondria [49] and the focusing of secretory vesicles in the tip domain (unpublished work from our laboratories and [49]). Results in the present manuscript, coupled to current Q4 literature, suggest that TGase-modified microtubules represent a subset of microtubules more resistant to depolymerization and along which the activity of motor proteins is partly inhibited.

In conclusion, these in vitro experiments show that pollen TGase affects the organization and functioning of the cytoskeleton; we propose that the activity of TGase might be modulated in vivo (under less extreme conditions) to exert a regulatory role on pollen tube growth.

\section{FUNDING}

This work was supported by the Italian Ministero dell'Università [grant numbers PRIN 2003 and PRIN 2005, http://prin.miur.it/] to the Dipartimento Biologia Evoluzionistica Sperimentale (DSF, University of Bologna) and by the Human Frontier Science Program (http://www.hfsp.org) to the Dipartimento Scienze Ambientali, University of Sienna.

\section{REFERENCES}

1 Malho, R., Liu, Q., Monteiro, D., Rato, C., Camacho, L. and Dinis, A. (2006) Signalling pathways in pollen germination and tube growth. Protoplasma 228, 21-30

2 Lovy-Wheeler, A., Cardenas, L., Kunkel, J. G. and Hepler, P. K. (2006) Differential organelle movement on the actin cytoskeleton in lily pollen tubes. Cell Motil. Cytoskeleton 64, 217-232

3 Lovy-Wheeler, A., Wilsen, K. L., Baskin, T. I. and Hepler, P. K. (2005) Enhanced fixation reveals the apical cortical fringe of actin filaments as a consistent feature of the pollen tube. Planta 221, 95-104

4 Cai, G. and Cresti, M. (2006) The microtubular cytoskeleton in pollen tubes: structure and role in organelle trafficking. In The Pollen Tube (Malho, R., ed.), pp. 157-175, Springer, Berlin-Heidelberg

5 Gibbon, B. C., Kovar, D. R. and Staiger, C. J. (1999) Latrunculin B has different effects on pollen germination and tube growth. Plant Cell 11, 2349-2364

6 Laitiainen, E., Nieminen, K. M., Vihinen, H. and Raudaskoski, M. (2002) Movement of generative cell and vegetative nucleus in tobacco pollen tubes is dependent on microtubule cytoskeleton but independent of the synthesis of callose plugs. Sex. Plant Reprod. 15, 195-204

7 Gossot, 0. and Geitmann, A. (2007) Pollen tube growth: coping with mechanical obstacles involves the cytoskeleton. Planta 226, 405-416

8 Wang, W., Vignani, R., Scali, M., Sensi, E. and Cresti, M. (2004) Post-translational modifications of $\alpha$-tubulin in Zea mays L. are highly tissue specific. Planta 218, 460-465

9 Takashi, R. (1988) A novel actin label: a fluorescent probe at glutamine-41 and its consequences. Biochemistry 27, 938-943

10 Folk, J. E., Park, M. H., Chung, S. I., Schrode, J., Lester, E. P. and Cooper, H. L. (1980) Polyamines as physiological substrates for transglutaminases. J. Biol. Chem. 255 , $3695-3700$

11 Folk, J. E. (1980) Transglutaminases. Annu. Rev. Biochem. 49, 517-531

12 Serafini-Fracassini, D. and Del Duca, S. (2008) Transglutaminases: widespread cross-linking enzymes in plants. Ann. Bot. (Lond.) 102, 145-152

13 Griffin, M., Casadio, R. and Bergamini, C. M. (2002) Transglutaminases: nature's biological glues. Biochem. J. 368, 377-396

14 Derrick, N. and Laki, K. (1966) Enzymatic labelling of actin and tropomyosin with ${ }^{14} \mathrm{C}$-labelled putrescine. Biochem. Biophys. Res. Commun. 22, 82-88

15 Klein, J. D., Guzman, E. and Kuehn, G. D. (1992) Purification and partial characterization of transglutaminase from Physarum polycephalum. J. Bacteriol. 174, 2599-2605

16 Robinson, N. J., Baker, P. N., Jones, C. J. and Aplin, J. D. (2007) A role for tissue transglutaminase in stabilization of membrane-cytoskeletal particles shed from the human placenta. Biol. Reprod. 77, 648-657

17 Pohjanpelto, P., Virtanen, I. and Holtta, E. (1981) Polyamine starvation causes disappearance of actin filaments and microtubules in polyamine-auxotrophic $\mathrm{CHO}$ cells. Nature 293, 475-477

18 Del Duca, S., Bregoli, A. M., Bergamini, C. and Serafini-Fracassini, D. (1997) Transglutaminase-catalyzed modification of cytoskeletal proteins by polyamines during the germination of Malus domestica pollen. Sex. Plant Reprod. 10, 89-95

19 Bagni, N., Adamo, P. and Serafini-Fracassini, D. (1981) RNA, proteins and polyamines during tube growth in germinating apple pollen. Plant Physiol. 68, 727-730

20 Della Mea, M., Serafini-Fracassini, D. and Duca, S. D. (2007) Programmed cell death: similarities and differences in animals and plants. A flower paradigm. Amino Acids $\mathbf{3 3}$ 395-404 
21 Iorio, R. A., Di Sandro, A., Scarpellini, A., Del Duca, S., Serafini-Fracassini, D. and Verderio, E. (2008) Visualisation of transglutaminase-mediated cross-linking activity in germinating pollen by laser confocal microscopy. Plant Biosystems http://www. informaworld.com/smpp/title $\sim$ content $=$ t713737104 $\sim \mathrm{db}=\mathrm{all} \sim \mathrm{tab}=$ issueslist $\sim$ branches $=142-$ v142 142, 360-365

22 Lilley, G. R., Skill, J., Griffin, M. and Bonner, P. L. (1998) Detection of $\mathrm{Ca}^{2+}$-dependent transglutaminase activity in root and leaf tissue of monocotyledonous and dicotyledonous plants. Plant Physiol. 117, 1115-1123

23 Yen, L.-F., Liu, X. and Cai, S. (1995) Polymerization of actin from maize pollen. Plant Physiol. 107, 73-76

24 Zhang, H., Liu, G.-Q. and Yen, L.-F. (1997) Purification and characterization of tubulin from Ginkgo pollen. Sex. Plant Reprod. 10, 136-141

25 Serafini-Fracassini, D., Del Duca, S. and D'Orazi, D. (1988) First evidence for polyamine conjugation mediated by an enzymic activity in plants. Plant Physiol. 87, 757-761

26 Hegyi, G., Mak, M., Kim, E., Elzinga, M., Muhlrad, A. and Reisler, E. (1998) Intrastrand cross-linked actin between GIn-41 and Cys-374. I. Mapping of sites cross-linked in F-actin by N-(4-azido-2-nitrophenyl) putrescine. Biochemistry 37, 17784-17792

27 Beninati, S., Piacentini, M., Argento-Cerù, M. P., Russo-Caia, S. and Autuori, F. (1985) Presence of di- and polyamines covalently bound to protein in rat liver. Biochim. Biophys. Acta 841, 120-126

28 Cai, G., Romagnoli, S., Moscatelli, A., Ovidi, E., Gambellini, G., Tiezzi, A. and Cresti, M. (2000) Identification and characterization of a novel microtubule-based motor associated with membranous organelles in tobacco pollen tubes. Plant Cell 12, 1719-1736

29 Laemmli, U. K. (1970) Cleavage of structural proteins during the assembly of the head of bacteriophage T4. Nature 227, 680-685

30 Towbin, H., Staehelin, T. and Gordon, J. (1979) Electrophoretic transfer of proteins from polyacrylamide gels to nitrocellulose sheets: procedure and some applications. Proc. Natl. Acad. Sci. U.S.A. 76, 4350-4354

31 Brown, R. E., Jarvis, K. L. and Hyland, K. J. (1989) Protein measurement using bicinchoninic acid: elimination of interfering substances. Anal. Biochem. 180, 136-139

32 Eli-Berchoer, L., Hegyi, G., Patthy, A., Reisler, E. and Muhlrad, A. (2000) Effect of intramolecular cross-linking between glutamine-41 and lysine-50 on actin structure and function. J. Muscle Res. Cell Motil. 21, 405-414

33 Hegyi, G., Michel, H., Shabanowitz, J., Hunt, D. F., Chatterjie, N., Healy-Louie, G. and Elzinga, M. (1992) Gln-41 is intermolecularly cross-linked to Lys-113 in F-actin by N-(4-azidobenzoyl)-putrescine. Protein Sci. 1, 132-144

34 Kim, S. Y., Chung, S. I. and Steinert, P. M. (1995) Highly active soluble processed forms of the transglutaminase 1 enzyme in epidermal keratinocytes. J. Biol. Chem. 270 , 18026-18035

Received 3 September 2008/14 November 2008; accepted 18 November 2008 Published as BJ Immediate Publication 18 November 2008, doi:10.1042/BJ20081781
35 Rouayrenc, J. F. and Travers, F. (1981) The first step in the polymerisation of actin. Eur. J. Biochem. 116, 73-77

36 Serafini-Fracassini, D., Del Duca, S. and Beninati, S. (1995) Plant transglutaminases. Phytochemistry 40, 355-365

37 Maccioni, R. B. and Arechaga, J. (1986) Transglutaminase (TG) involvement in early embryogenesis. Exp. Cell Res. 167, 266-270

38 Piredda, L., Farrace, M. G., Lo, B. M., Malorni, W., Melino, G., Petruzzelli, R. and Piacentini, M. (1999) Identification of tissue transglutaminase binding proteins in neural cells committed to apoptosis. FASEB J. 13, 355-364

39 Kim, E., Bobkova, E., Miller, C. J., Orlova, A., Hegyi, G., Egelman, E. H., Muhlrad, A. and Reisler, E. (1998) Intrastrand cross-linked actin between Gln-41 and Cys-374. III. Inhibition of motion and force generation with myosin. Biochemistry 37, 17801-17809

40 Hegyi, G. and Belagyi, J. (2006) Intermonomer cross-linking of F-actin alters the dynamics of its interaction with $\mathrm{H}$-meromyosin in the weak-binding state. FEBS J. $\mathbf{2 7 3}$ 1896-1905

41 Oriol-Audit, C. (1978) Polyamine-induced actin polymerization. Eur. J. Biochem. 87, 371-376

42 Dunn, S., Morrison, E. E., Liverpool, T. B., Molina-Paris, C., Cross, R. A., Alonso, M. C. and Peckham, M. (2008) Differential trafficking of Kif5c on tyrosinated and detyrosinated microtubules in live cells. J. Cell Sci. 121, 1085-1095

43 Rosenbaum, J. (2000) Cytoskeleton: functions for tubulin modifications at last. Curr. Biol. 10, R801-R803

44 Cardenas, L., Lovy-Wheeler, A., Wilsen, K. L. and Hepler, P. K. (2005) Actin polymerization promotes the reversal of streaming in the apex of pollen tubes. Cell Motil. Cytoskeleton 61, 112-127

45 Kang, H. and Cho, Y. D. (1996) Purification and properties of transglutaminase from soybean (Glycine max) leaves. Biochem. Biophys. Res. Commun. 223, 288-292

46 Feijò, J. A., Sainhas, J., Hackett, G. R., Kunkel, J. G. and Hepler, P. K. (1999) Growing pollen tubes possess a constitutive alkaline band in the clear zone and $a$ growth-dependent acidic tip. J. Cell Biol. 144, 483-496

47 Cai, G., Ovidi, E., Romagnoli, S., Vantard, M., Cresti, M. and Tiezzi, A. (2005) Identification and characterization of plasma membrane proteins that bind to microtubules in pollen tubes and generative cells of tobacco. Plant Cell Physiol. 46, 563-578

48 He, Y., Wetzstein, H. Y. and Palevitz, B. A. (1995) The effect of a triazole fungicide, propiconazole, on pollen germination, the growth and cytoskeletal distribution in Tradescantia virginiana. Sex. Plant Reprod. 8, 210-216

49 Romagnoli, S., Cai, G., Faleri, C., Yokota, E., Shimmen, T. and Cresti, M. (2007) Microtubule- and actin filament-dependent motors are distributed on pollen tube mitochondria and contribute differently to their movement. Plant Cell Physiol. $\mathbf{4 8}$ 345-361

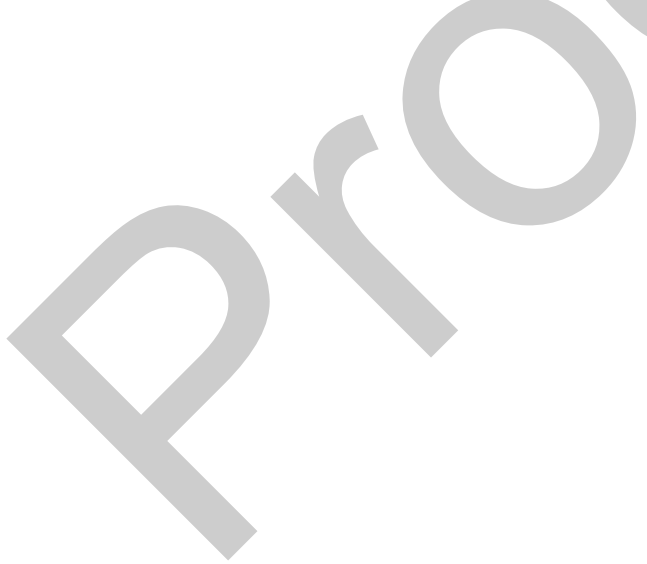




\section{Proof Delivery Form}

Journal and Article number: BIC 407

BJ reference: BJ2008/1781

Number of colour figures: Nil

Number of pages (not including this page): 2

This proof contains supplementary online material.

\section{Biochemical Journal}

Please print out your proof, mark any corrections needed, and return it, together with the offprint order form, by FAX to $+44(0) 2072804169$ as soon as possible (no later than 48 hours after receipt).

- You are responsible for correcting your proofs! Errors not found may appear in the journal.

- The proof is sent to you for correction of typographical errors only, and revision of the substance of the text is not permitted.

- Please answer carefully any queries from the subeditor.

- A new copy of a figure must be provided if correction is required.

Notes:

1. The quality of half-tone and colour figures will be checked by the editorial office.

2. The volume number indicated on the proof is tentative only.

3. If you have any comments, however minor, on the handling of your paper, please let us know. Please quote the paper's reference number when doing so.

4. If you have any queries, please contact the editorial office by email (editorial@portlandpress.com) or by telephone on 02072804110 (+44 2072804110 from outside the U.K.).

\section{Author queries:}

Typesetter queries:

\section{Non-printed material:}

Primary: S6

Secondary: S7 


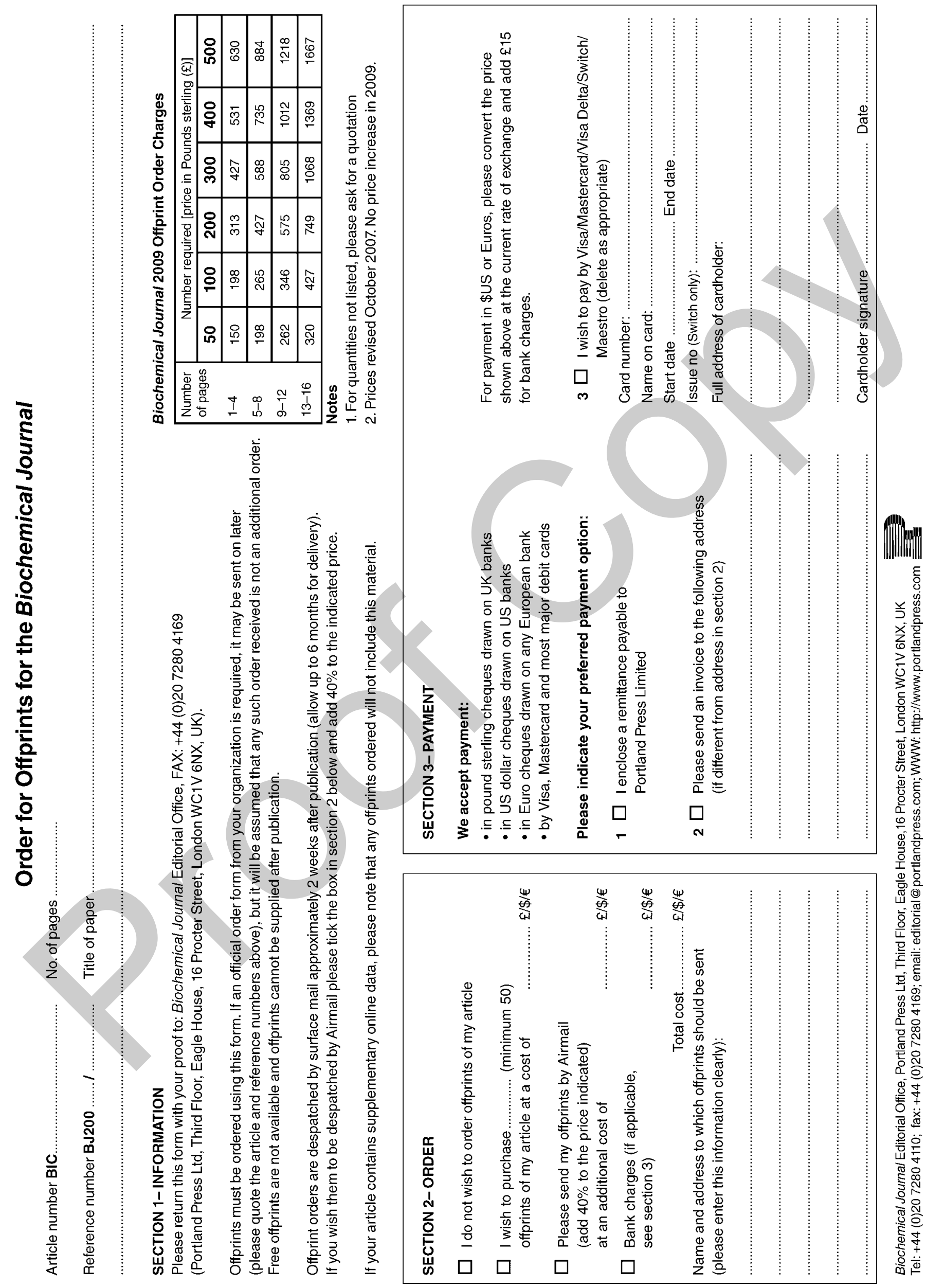




\section{SUPPLEMENTARY ONLINE DATA}

\section{Effects of post-translational modifications catalysed by pollen transglutaminase on the functional properties of microtubules and actin filaments}

Stefano DEL DUCA*, Donatella SERAFINI-FRACASSINI*, Philip BONNER $\dagger$, Mauro CRESTI $\ddagger$ and Giampiero CAl $\ddagger^{1}$

${ }^{*}$ Dipartimento di Biologia Evoluzionistica Sperimentale, Sede Botanica, University of Bologna, via Irnerio 42, 40126 Bologna, Italy, $†$ School of Biomedical and Natural Sciences, Nottingham Trent University, Nottingham NG11 8NS, U.K., and łDipartimento Scienze Ambientali, University of Sienna, via Mattioli 4, 53100 Siena, Italy

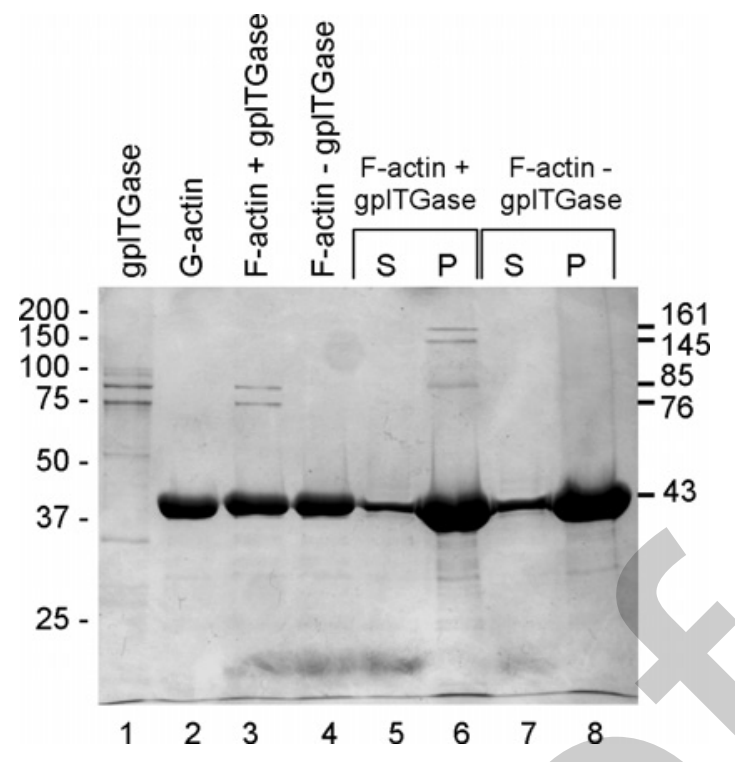

Figure S1 Enzyme activity of gpITGase on F-actin

Enzymatic assay in the presence/absence of gplTGase and FITC-cadaverine. Lane 1, gpITGase $(1 \mu \mathrm{g})$; lane 2, monomeric actin $(10 \mu \mathrm{g})$; lane 3 , filamentous actin $(10 \mu \mathrm{g})$ incubated with gplTGase; lane 4, control of F-actin without gp/TGase $(10 \mu \mathrm{g})$. Lane 5 , supernatant in the presence of gplTGase; lane 6, corresponding pellet; lane 7, supernatant in the absence of gpITGase; lane 8, corresponding pellet. The high molecular mass aggregates (arrowheads) also formed under this experimental condition and showed a molecular mass (85, 145, and $161 \mathrm{kDa})$ similar to those obtained with pollen TGase. The gel is Coomassie Blue-stained. Molecular masses of the standards and proteins of interest are shown on the left and right respectively in $\mathrm{kDa}$.
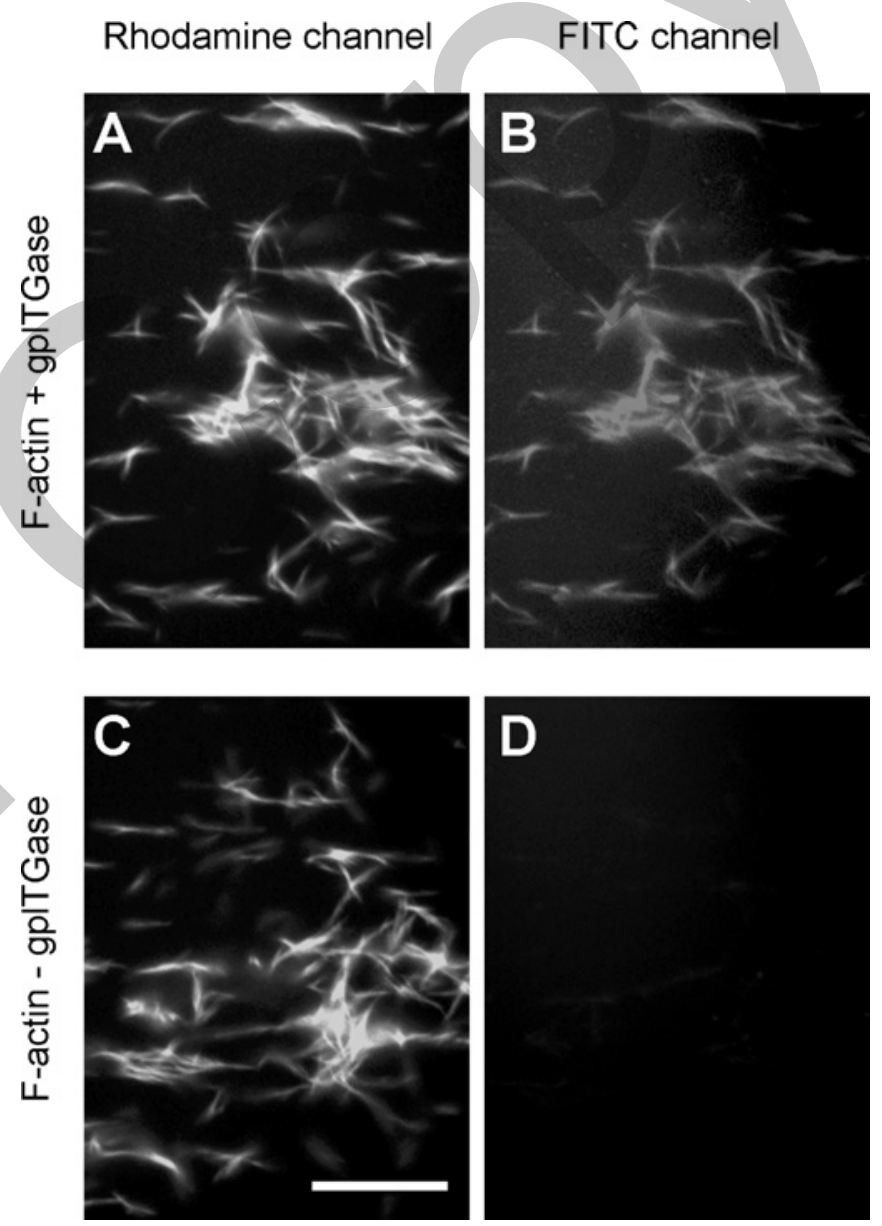

Figure S2 Incorporation of FITC-cadaverine in rabbit actin by gplTGase

(A) Rhodamine-labelled F-actin obtained in the presence of gplTGase and FITC-cadaverine (viewed in the rhodamine filter). (B) Same view field observed in the FITC filter. This sample corresponded to the pellet of lane 6 in Figure S1. (C) Rhodamine-labelled F-actin obtained in the absence of glITGase but in presence of FITC-cadaverine (rhodamine filter). (D) Same view field observed in the FITC filter. This sample corresponds to the pellet of lane 8 in Figure S1. Scale bar: $5 \mu \mathrm{m}$. 


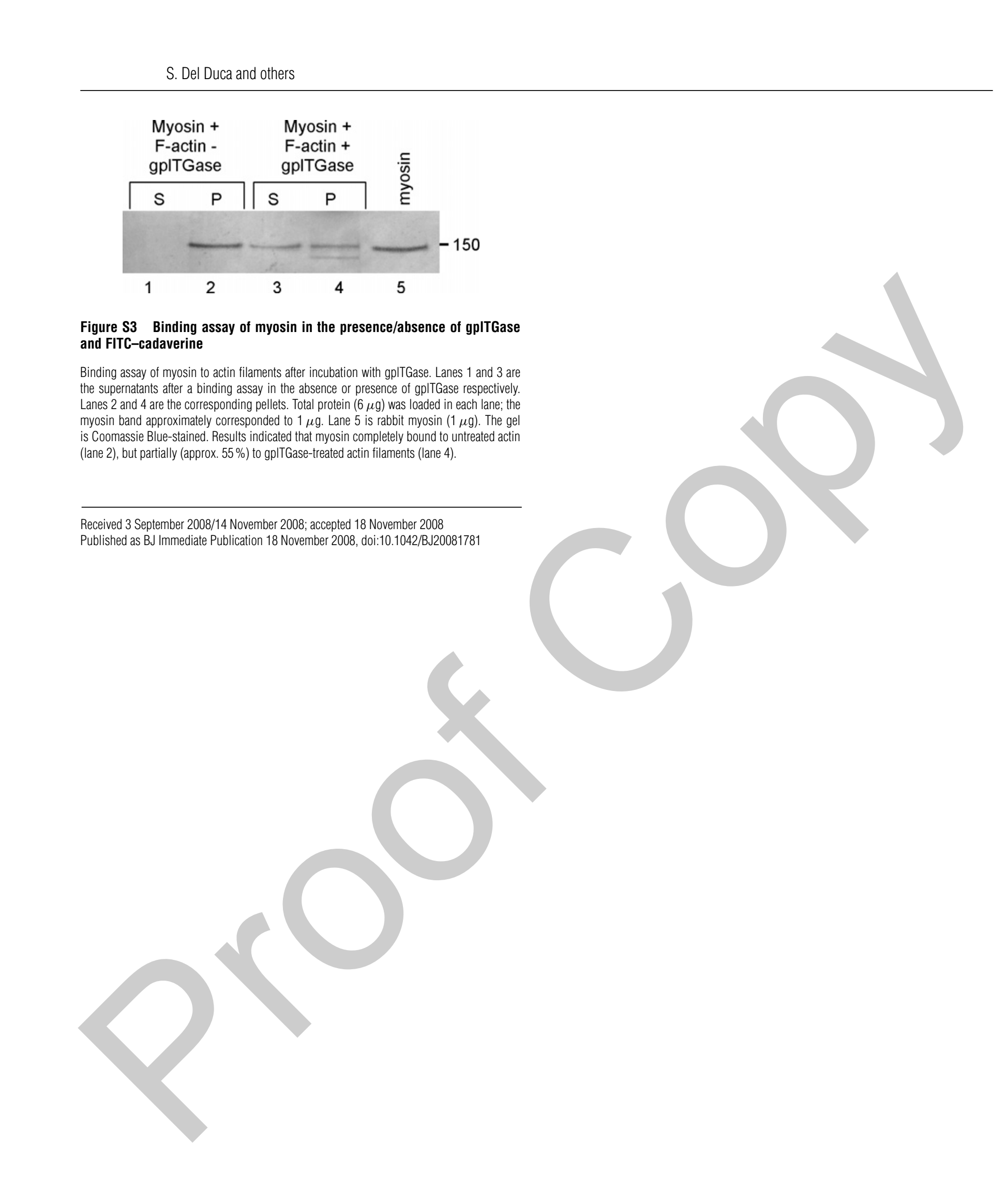

